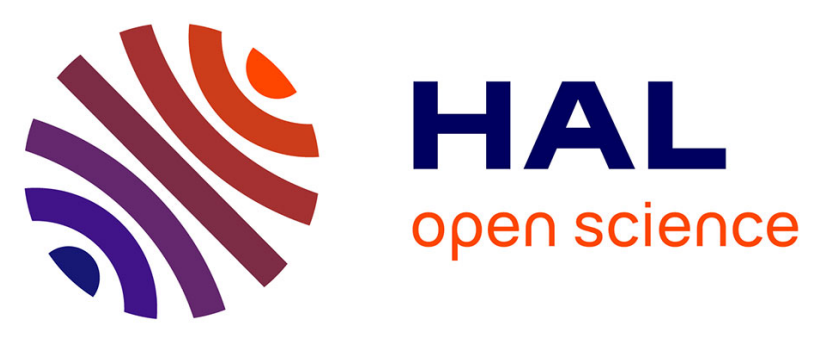

\title{
Antidiabetic, antioxidant and anti inflammatory properties of water and n-butanol soluble extracts from Saharian Anvillea radiata in high-fat-diet fed mice
}

Chouaib Kandouli, Mathieu Cassien, Anne Mercier, Caroline Delehedde, Emilie Ricquebourg, Pierre Stocker, Mourad Mekaouche, Zineb Leulmi, Aicha Mechakra, Sophie Thétiot-Laurent, et al.

\section{To cite this version:}

Chouaib Kandouli, Mathieu Cassien, Anne Mercier, Caroline Delehedde, Emilie Ricquebourg, et al.. Antidiabetic, antioxidant and anti inflammatory properties of water and n-butanol soluble extracts from Saharian Anvillea radiata in high-fat-diet fed mice. Journal of Ethnopharmacology, 2017, 10.1016/j.jep.2017.06.042 . hal-01552635

\section{HAL Id: hal-01552635 \\ https://hal-amu.archives-ouvertes.fr/hal-01552635}

Submitted on 3 Jul 2017

HAL is a multi-disciplinary open access archive for the deposit and dissemination of scientific research documents, whether they are published or not. The documents may come from teaching and research institutions in France or abroad, or from public or private research centers.
L'archive ouverte pluridisciplinaire HAL, est destinée au dépôt et à la diffusion de documents scientifiques de niveau recherche, publiés ou non, émanant des établissements d'enseignement et de recherche français ou étrangers, des laboratoires publics ou privés. 


\section{Author's Accepted Manuscript}

Antidiabetic, antioxidant and anti inflammatory properties of water and $n$-butanol soluble extracts from Saharian Anvillea radiata in high-fat-diet fed mice

Chouaib Kandouli, Mathieu Cassien, Anne Mercier, Caroline Delehedde, Emilie Ricquebourg, Pierre Stocker, Mourad Mekaouche, Zineb Leulmi,

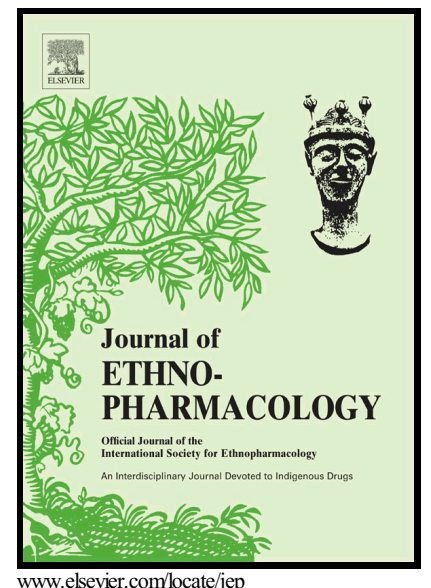
Aicha Mechakra, Sophie Thétiot-Laurent, Marcel Culcasi, Sylvia Pietri

PII: S0378-8741(17)30828-0

DOI: $\quad$ http://dx.doi.org/10.1016/j.jep.2017.06.042

Reference: JEP10920

To appear in: Journal of Ethnopharmacology

Received date: 1 March 2017

Revised date: 23 May 2017

Accepted date: 26 June 2017

Cite this article as: Chouaib Kandouli, Mathieu Cassien, Anne Mercier, Carolin Delehedde, Emilie Ricquebourg, Pierre Stocker, Mourad Mekaouche, Zinel Leulmi, Aicha Mechakra, Sophie Thétiot-Laurent, Marcel Culcasi and Sylvii Pietri, Antidiabetic, antioxidant and anti inflammatory properties of water and $n$ butanol soluble extracts from Saharian Anvillea radiata in high-fat-diet fed mice Journal of Ethnopharmacology, http://dx.doi.org/10.1016/j.jep.2017.06.042

This is a PDF file of an unedited manuscript that has been accepted fo publication. As a service to our customers we are providing this early version o the manuscript. The manuscript will undergo copyediting, typesetting, an review of the resulting galley proof before it is published in its final citable form Please note that during the production process errors may be discovered whic could affect the content, and all legal disclaimers that apply to the journal pertain 
Antidiabetic, antioxidant and anti inflammatory properties of water and $n$-butanol soluble extracts from Saharian Anvillea radiata in high-fat-diet fed mice

Chouaib Kandouli ${ }^{\mathrm{a}, \mathrm{b}}$, Mathieu Cassien ${ }^{\mathrm{a}}$, Anne Mercier ${ }^{\mathrm{a}}$, Caroline Delehedde ${ }^{\mathrm{a}}$, Emilie Ricquebourg $^{\mathrm{a}}$, Pierre Stocker ${ }^{\mathrm{a}}$, Mourad Mekaouche $^{\mathrm{c}}$, Zineb Leulmi $^{\mathrm{b}}$, Aicha Mechakra ${ }^{\mathrm{b}}$, Sophie Thétiot-Laurent ${ }^{\mathrm{a}}$, Marcel Culcasi ${ }^{\mathrm{a}}$, Sylvia Pietri ${ }^{\mathrm{a} *}$

${ }^{a}$ Aix Marseille Univ, CNRS, ICR, SMBSO, Marseille, France

${ }^{\mathrm{b}}$ Laboratoire de Biologie et Environnement, Faculté des Sciences de la Nature et de la Vie, Université Frères Mentouri, BP 325, Route Ain El Bey, 25017 Constantine, Algérie

'Aix Marseille Univ, CNRS, CRN2M, Hôpital Nord, Marseille, France

*Corresponding author. S. Pietri, Ph.D. Aix Marseille Univ, CNRS, ICR UMR 7273, Institut de Chimie Radicalaire, Sondes Moléculaires en Biologie et Stress Oxydant, Service 522, Faculté des Sciences de Saint-Jérôme, Avenue Escadrille Normandie-Niemen, 13397 Marseille Cedex 20 - France. Tel: 33 (0)4 912885 79; Fax: 33 (0)4 912887 58. sylvia.pietri@univ-amu.fr

\section{Abstract \\ Ethnopharmacological relevance:}

According to Saharian traditional medicine, Anvillea radiata Coss. \& Dur. (Asteraceae) has been valued for treating a variety of ailments such as gastro-intestinal, liver and pulmonary diseases, and has gained awareness for its beneficial effect on postprandial hyperglycemia. However, to best of our knowledge, no detailed study of the antidiabetic curative effects of this plant has been conducted yet.

Aim of the study: 
To determine the hypoglycemic and antidiabetic effect of dietary supplementation with Anvillea radiata extracts on high-fat-diet (HFD)-induced obesity and insulin resistance in C57BL/6J mice in relation with antioxidant, anti-inflammatory, pancreatic beta-cells and skeletal muscle protection, and digestive enzyme inhibiting properties.

\section{Materials and methods:}

Six extracts (water soluble and organic) from aerial parts of the plant were analyzed phytochemically (total phenolic and flavonoid content) and screened for in vitro superoxide (by chemiluminescence) and hydroxyl radical (by electron paramagnetic resonance spin-trapping) scavenging, antioxidant (DPPH, TRAP and ORAC assays), xanthine oxidase, metal chelating, $\alpha$ amylase and $\alpha$-glucosidase inhibitory property, and protective effects on copper-induced lipoprotein oxidation. Then selected hydroalcoholic and aqueous extracts were assessed for toxicity in normal human lung fibroblasts and A549 cancer cells using FMCA and MTT assays. Two water-soluble extracts having the best overall properties were assessed for their (i) protective effect at $1-15 \mu \mathrm{g} / \mathrm{mL}$ on metabolic activity of rat insulinoma-derived INS- 1 cells exposed to hyperglycemic medium, and (ii) acute hypoglycemic effect on 16-weeks HFDinduced diabetic mice. Then diabetic mice were administered HFD supplemented by extracts (up to $150 \mathrm{mg} / \mathrm{kg} / \mathrm{day}$ ) for 12 additional weeks using standard diet as control and the antidiabetic drug, metformin $(150 \mathrm{mg} / \mathrm{kg})$, as positive control. Then the antidiabetic, anti-inflammatory and antioxidant activity of extracts were determined.

\section{Results:}

Of the highly efficient polyphenolics-enriched hydroalcoholic and ethyl acetate extracts, the lyophilized aqueous (AQL) and butanol extracts were not toxic in cells $(\leq 400 \mu \mathrm{g} / \mathrm{mL})$ or when given orally in normal mice ( $\leq 2000 \mathrm{mg} / \mathrm{kg}$ ), exerted a dose-dependent hypoglycemic action in diabetic mice, which was maximal at the dose of $150 \mathrm{mg} / \mathrm{kg}$. Upon administering this dose for 12 weeks, both extracts significantly ameliorated body weight control capacity, recovery of plasma glucose and insulin level, reduced oxidative stress in blood, myocardial and skeletal muscles, and improved hyperlipidemic and inflammatory status. Moreover, diabetes-related complications were optimally ameliorated by oral therapy based on halved doses $(75 \mathrm{mg} / \mathrm{kg})$ of a mixture of $\mathrm{AQL}$ and metformin. 


\section{Conclusions:}

Current investigation supports the traditional medicinal usage of Anvillea radiata and suggests that both readily accessible and low-cost bio-extracts have the potency to develop an antihyperglycemic, antihyperlipidemic and protective agent against beta-cells and muscle dysfunction at doses compatible with the common practices of indigenous people for the management of metabolic disorders.

Graphical abstract
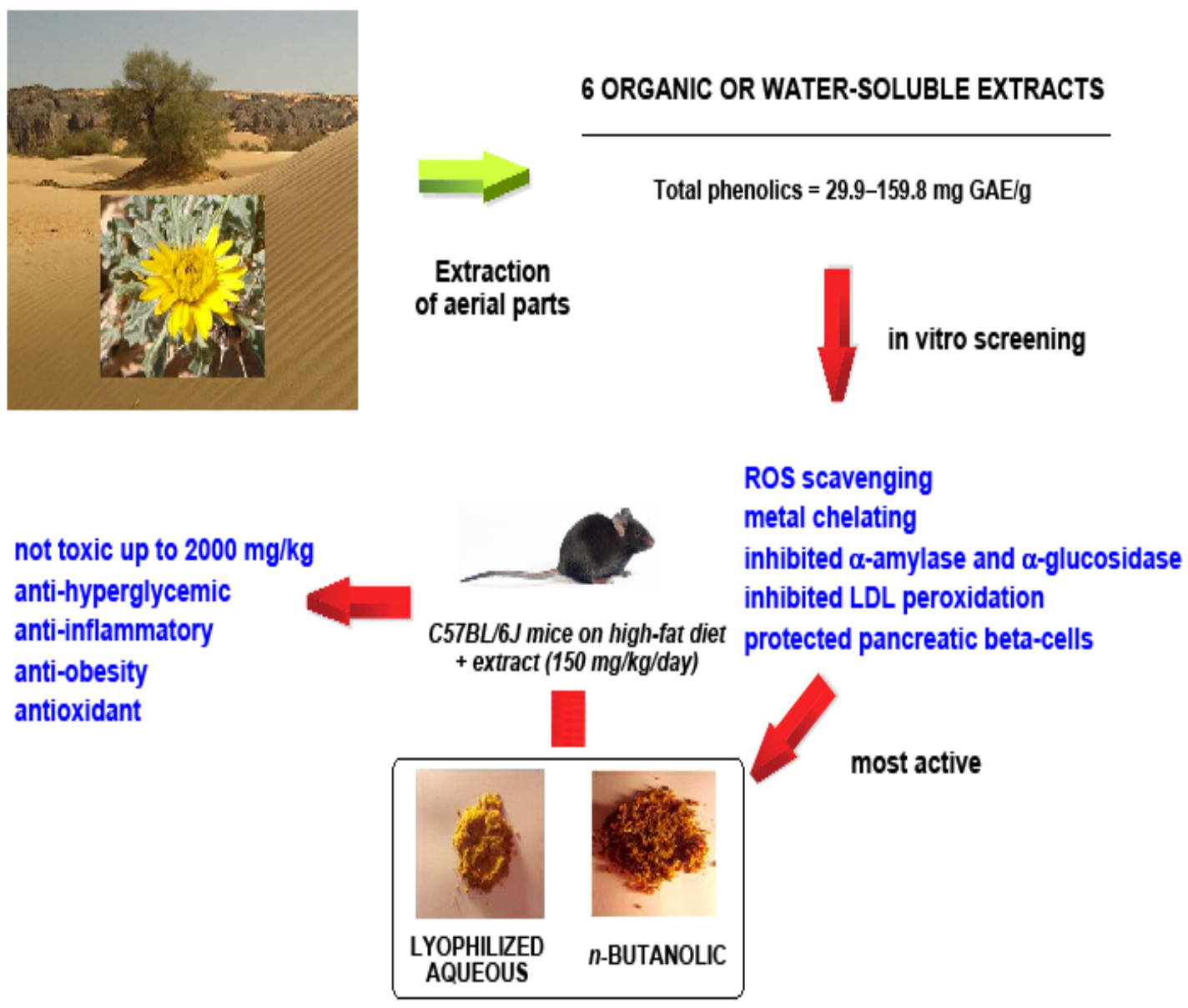
Keywords:

Anvillea radiata, Medicinal plants, Total phenolics, Pancreatic beta-cells, C57/BL6J mice, Type 2 diabetes.

\section{Introduction}

For centuries, plants have been exploited as remedies, the knowledge on their pharmacological activities being primarily based on empirical findings. Over the recent past, interest in identifying druggable metabolites from plants has also inspired the design of modern synthetic lead drugs for the treatment of non-communicable diseases, including cancer, cardiovascular disease and diabetes mellitus (Bailey et al., 1989; Gurib-Fakim, 2006). For instance, it is estimated that more than $70 \%$ of the population in developed or developing countries currently use medicinal plants alone or in combination with allopathic drugs (GuribFakim, 2006; Lesgards et al., 2014) and that almost $80 \%$ of diabetics worldwide still depend exclusively on herbal folk medicine (Rios et al., 2015).

Surveys of traditional Saharian medicines have been conducted with the help of local populations, leading to inventories of dozens of indigenous medicinal plants and their therapeutic indications (Hammiche and Maiza, 2006; Boudjelal et al., 2013; Fakchich and Elachouri, 2014). Notably, Anvillea radiata Coss. \& Dur (Asteraceae), which is mainly distributed in northern Africa, is used by populations and traditional healers in infusions or decoctions of the leaves and flowers to treat a variety of ailments such as chest cold, gastrointestinal, liver and pulmonary disorders, and postprandial hyperglycemia (Hammiche and Maiza, 2006; Ghourri et al., 2013; Fakchich and Elachouri, 2014). Previous phytochemical reports identified two main families in A. radiata aerial parts, i.e., germacranolides such as $9 \alpha$-hydroxyparthenolide and $8 \alpha, 9 \alpha$ epoxyparthenolide isolated in chloroform extracts, and a less abundant fraction of phenolics (e.g., derivatives of dicaffeoylquinic acid), including flavonoids (both glycosides and aglycones) in aqueous/alcoholic extracts (Dendougui et al., 2006; Moumou et al., 2014; Destandau et al., 2015; Boukhris et al., 2016). Aside from these active compounds, saponins, tannins, fatty acids, and various types of secondary metabolites, including sterols, terpenoids, etc. were found in $A$. 
radiata extracts using polar solvents (Lakhdar et al., 2013; Hamada and Ladjel, 2015), many of them having potential biological and antioxidant activities. Germacranolides from $A$. radiata demonstrated antitumoral, anti-inflammatory and antibacterial properties (Moumou et al., 2014) and up to now laboratory investigation of the biological activities of whole material preparations of the plant has focused on the antimicrobial (Bammou et al., 2015; Hamada and Ladjel, 2015) and antifungal (Lakhdar et al., 2013) properties of aqueous and organic extracts.

Plant-derived phenolics and terpenoids such as those prevailing in A. radiata polar extracts are known antioxidants acting by terminating free radical chains and/or inactivating metal ion catalysis of lipid peroxidation, and their presence is of great pharmacological and therapeutic interest in several pathologies where overproduction of reactive oxygen species (ROS) has been implicated (Pietri et al., 1997; Del Rio et al., 2013). In this regard, A. radiata decoctions or as dried powder are commonly ingested in Saharian traditional medicine against diabetes (Hammiche and Maiza, 2006; Ghourri et al., 2013; Fakchich and Elachouri, 2014), a pathology associated with the setting of sustained oxidative stress and altered antioxidant levels (Giacco and Brownlee, 2010). This role of ROS formation in the pathogenesis of type 2 diabetes mellitus complications such as cardiovascular and renal dysfunction, and neurological damage is well established (Meigs, 2010). Antioxidant and antihyperglycemic therapeutic strategies based on natural compounds are emerging which can provide long-lasting control of glycemia with minimal side effects (Giacco and Brownlee, 2010; Rios et al., 2015). In connection, studies on experimental diabetes in animals have reported the hypoglycemic action of extracts or isolated flavone constituents in other species belonging to the Asteraceae family, the efficiency being however strongly depending on the choice of the model and administration procedure (Bnouham et al., 2006).

To set up Anvillea radiata extraction procedures allowing for an improved standardization of active compounds, the objectives of this study were thus: (i) to determine the phenolic profiles in nonpolar vs polar extracts and their associated inhibition properties towards a series of determinants of ROS and cytotoxicities in normal and cancer cultured cells; (ii) to assess for the first time the in vitro $\alpha$-amylase and $\alpha$-glucosidase inhibitory activities of the extracts; (iii) to evaluate their protective effect on cultured rat beta-cells exposed to hyperglycemic conditions, and (iv) to evaluate the effect of oral administration of two potentially druggable extracts on 
hyperglycemia, oxidative stress, metabolic and inflammatory biomarkers of type 2 diabetes and obesity in a model of high-fat fed C57/BL6J mice.

\section{Materials and methods}

\subsection{Standards, reagents and cell culture media}

HPLC grade solvents were used throughout, including methanol and ethyl acetate which were from Acros Organics (Fisher Scientific, Illkirch, France) and $n$-butanol and petroleum ether $\left(40-60^{\circ} \mathrm{C}\right)$ which were from VWR Chemicals (Fontenay sous Bois, France). Deionized water obtained from a Purelab station (Elga, France) was used throughout. Normal and extractcontaining cell culture media were passed through a 2- $\mu \mathrm{M}$ Millipore filter before use. 2,2'Azobis(2-amidinopropane) dihydrochloride (AAPH), allopurinol and phenolic standards (Trolox, quercetin, naringenin, gallic, caffeic, ferulic and sinapic acids) were purchased from Acros. Phosphate-buffered saline (PBS) and other buffers, xanthine, xanthine oxidase (XO; from buttermilk), 2-thiobarbituric acid (TBA), diethylenetriaminepentaacetic acid (DTPA), 3-(4,5dimethyl-2-thiazolyl)-2,5-diphenyl-2 $\mathrm{H}$-tetrazolium bromide (MTT), hydrogen peroxide $\left(\mathrm{H}_{2} \mathrm{O}_{2}\right)$, adenosine triphosphate (ATP), 2-deoxy-D-ribose (deoxyribose), the spin trap 5,5-dimethyl-1pyrroline $N$-oxide (DMPO) and all other reagents were purchased from Sigma-Aldrich (Saint Quentin Fallavier, France). Media for cell culture were from Gibco Life Technologies (Thermo Fisher Scientific), including Dulbecco's modified Eagle's medium (DMEM), Roswell Park Memorial Institute medium (RPMI 1640) and GlutaMax, or Lonza (Arch Water Products, Amboise, France), including fibroblast basal medium (FBM) and growth factors (FGM; Clonetics). Hypoglycemic drugs metformin hydrochloride (Met; 99.9\%, pharmagrade; from UniPex Pharmaceuticals, France) and glibenclamide (from TCI Europe, Belgium) were used as positive controls in antidiabetic studies.

\subsection{Plant material}


The aerial parts (flowers and leaves) of Anvillea radiata were collected in april 2013 in the area of El Oued, in the Algerian part of Sahara (altitude, $69 \mathrm{~m}$ ). The main information (local name, collected parts of plant, traditional methods of preparation and usual medicinal uses and administration) were obtained from local inhabitants having ancestral knowledge of the curative properties of the plant. The sample was identified by Prof. N. Khalfallah (Laboratoire de Génétique, Biochimie, et Biotechnologies Végétales, Université Frères Mentouri (UFM), Constantine, Algeria). A voucher specimen (LBE13/01) has been deposited in the herbarium of the Faculty of Natural and Life Sciences at UFM. The plant material was dried at ambient temperature in the dark for 30 days and stored in a dry place prior to use.

\subsection{Plant material preparation}

\subsubsection{Lyophilized aqueous extract}

The dried plant material $(10 \mathrm{~g})$ was suspended in $200 \mathrm{~mL}$ of hot water and stirred for 30 min. The resulting extract was filtered, frozen with liquid $\mathrm{N}_{2}$ and lyophilized (Cryotec lyophilizer model Cosmos, Saint-Gély-du-Fesc, France) at $-80{ }^{\circ} \mathrm{C}$. This lyophilized aqueous extract (AQL) was obtained in $\sim 15 \% \mathrm{w} / \mathrm{w}$ yield and was stored at $-20{ }^{\circ} \mathrm{C}$ until analysis.

\subsubsection{Organic extracts}

A schematic diagram for the preparation of organic extracts of $A$. radiata is shown in Fig. 1. The dried plant material $(200 \mathrm{~g})$ was extracted with $1.2 \mathrm{~L}$ of methanol for $24 \mathrm{~h}$ at room temperature. After filtration of the residue the above procedure was repeated twice and the combined extracts were evaporated at $37^{\circ} \mathrm{C}$ until dryness using a rotary evaporator to give the methanol-soluble extract $(25.75 \mathrm{~g}, 12.8 \% \mathrm{w} / \mathrm{w})$. Then the methanol extract was treated with 300 $\mathrm{mL}$ of hot water to dissolve polyphenols, filtered and the resulting aqueous solution was first treated with petroleum ether (PE; $4 \times 100 \mathrm{~mL}$ ) to remove lipids and then successively partitioned with ethyl acetate $(4 \times 100 \mathrm{~mL})$, and $n$-butanol $(4 \times 100 \mathrm{~mL})$ according to previous procedures (Koleva et al., 2002; Bammou et al., 2015). After rotary evaporation under vacuum the following fractions were obtained: PE-soluble extract (1.9 g, 0.95\% w/w), ethyl acetate-soluble extract (2.8 
$\mathrm{g}, 1.4 \% \mathrm{w} / \mathrm{w})$, and $n$-butanol-soluble extract $(2.9 \mathrm{~g}, 1.4 \% \mathrm{w} / \mathrm{w})$. The residual aqueous layer was frozen with liquid $\mathrm{N}_{2}$ and lyophilized to yield the aqueous residual (AR) fraction (12 g, 6\% w/w). All these extracts were stored at $-20^{\circ} \mathrm{C}$ until analysis.

\subsection{Total phenolic content (TPC) and total flavonoid content (TFC) of extracts}

The TPC of each extract were determined using a reported procedure (Singleton et al., 1999) with minor modification. Samples $(20 \mu \mathrm{L})$ dissolved in methanol at $0.1 \mathrm{mg} / \mathrm{mL}$ were mixed with $100 \mu \mathrm{L}$ of a solution of the Folin-Ciocalteu reagent (Sigma-Aldrich; $0.2 \mathrm{~N}$ in distilled water), the mixtures were vortexed for $5 \mathrm{~min}$ and $80 \mu \mathrm{L}$ of an aqueous sodium carbonate solution $(75 \mathrm{~g} / \mathrm{L})$ was added. After $2 \mathrm{~h}$ incubation at room temperature the absorbance of the supernatant was read at $760 \mathrm{~nm}$ using a UV-visible spectrophotometer. The TPC was evaluated using a gallic acid calibration curve in methanol and the results are expressed as milligrams of gallic acid equivalents (GAE) per gram of extract weight.

The TFC of each extract was determined according to a reported procedure (Ordonez et al., 2006). Samples $(100 \mu \mathrm{L})$ dissolved in ethanol at $0.5 \mathrm{mg} / \mathrm{mL}$ were mixed with $100 \mu \mathrm{L}$ of ethanol containing $2 \%$ aluminium chloride. After $1 \mathrm{~h}$ incubation at room temperature the absorbance was read at $420 \mathrm{~nm}$. The TFC was evaluated using a rutin calibration curve in ethanol and the results are expressed as milligrams of rutin equivalents (RUE) per gram of extract weight.

\subsection{HPLC analysis of phenolic compounds}

To separate phenolic compounds a Merck Hitachi system consisting of a LaChrom L-7000 interface module and a L-7455 photodiode array detector controlled by the EZ Chrome chromatography manager software was used. For each fraction $(2 \mathrm{mg} / \mathrm{mL}$ in methanol), the average amounts of phenolic compounds were calculated from standard calibration curves obtained at the maximum UV absorbances of-flavonoids, hydroxybenzoic and hydroxycinnamic compounds, and were quantified as GAE, caffeic acid equivalents (CAE) and RUE per gram of extract weight, respectively. 
Reverse phase HPLC was carried out at room temperature on a Htec RP-18 column (250 $\mathrm{mm} \times 4 \mathrm{~mm} ; 5 \mu \mathrm{m}$; Macherey-Nagel, France) using a gradient with a flow rate of $0.8 \mathrm{~mL} / \mathrm{min}$. Gradient: solvent A ( $0.05 \%$ phosphoric acid in water, $\mathrm{pH} 2.6$ ), solvent $\mathrm{B}$ (methanol): $0-45 \mathrm{~min}$, $30-60 \% \mathrm{~B}$; $45-50 \mathrm{~min}, 60 \% \mathrm{~B}$; 50-51 min, 30\% B; 51-57 min, 30\% B.

\subsection{Antioxidant assays}

\subsubsection{2,2-Diphenyl-1-picrylhydrazyl (DPPH) radical scavenging assay}

For each extract a DPPH assay was carried out using a reported procedure (Alencar et al., 2008). Aliquots of each extract dissolved in methanol (20-660 $\mu \mathrm{g} / \mathrm{mL}$, final concentration) were mixed with $200 \mu \mathrm{L}$ of a fresh DPPH solution (Sigma-Aldrich; $0.126 \mathrm{mM}$ ) in methanol and the final volume was adjusted to $300 \mu \mathrm{L}$. After stirring the mixtures for 3-90 min at room temperature in the dark the absorbance was monitored at $517 \mathrm{~nm}$ on a microplate reader (TECAN infinite M200, Switzerland) until a plateau was reached. Percent DPPH scavenged was calculated using eq 1

Inhibition $(\%)=\left[100 \times\left(A_{0}-A\right) / A_{0}\right]$

where $A_{0}$ is the baseline value for neat DPPH in methanol and $A$ is the absorbance in the presence of a given concentration of the tested extract. $\mathrm{IC}_{50}$ values (the concentration resulting in $50 \%$ DPPH scavenging) were calculated (in $\mu \mathrm{g} / \mathrm{mL}$ ) by non-linear fitting of dose-response curves and $\mathrm{TIC}_{50}$ values were derived as the time (in min) required to reach the steady state for a concentration equal to $\mathrm{IC}_{50}$.

\subsubsection{Total reactive antioxidant potential (TRAP)}

TRAP was determined in Tris-HCl buffer (0.1 M, pH 7.4) as described (Cassien et al., 2016) using fresh stock luminol solutions kept in the dark at $4{ }^{\circ} \mathrm{C}$ until use. Peroxyl radicals were generated by heating AAPH $(150 \mathrm{mM}$ in $10 \mathrm{~mL}$ Tris- $\mathrm{HCl})$ at $37^{\circ} \mathrm{C}$ for $30 \mathrm{~min}$. Once cooled at room temperature, this solution can be used for up to $20 \mathrm{~min}$. In this order, $2 \mathrm{~mL}$ of AAPH solution, $0.5 \mathrm{~mL}$ of luminol solution $(13 \mu \mathrm{M})$, and $0.5 \mathrm{~mL}$ of a Tris-HCl:DMSO (100:1 v/v) solution of each extract $(0.4-25 \mu \mathrm{g} / \mathrm{mL}$, final concentration) were added and the mixture was 
stirred for $20 \mathrm{~s}$ at room temperature. Luminescence was recorded at room temperature (TitertekBerthold Sirius luminometer, Pforzheim, Germany). In the assay Trolox was the reference and the TRAP was obtained by integrating the area under curve (AUC) for sample and blank solutions (all reactants except test fraction) and the results are expressed as $\mu$ mole Trolox equivalents (TE) per gram of extract weight or TE (standards).

\subsubsection{Oxygen radical absorbing capacity (ORAC) assay}

The assay was performed in microplates according to modifications of previous methods (Dávalos et al., 2004). A fluorescein stock solution $(0.821 \mathrm{mM})$ was prepared in PBS $1 \mathrm{X}$ and stored at $4{ }^{\circ} \mathrm{C}$. Solutions of AAPH $(153 \mathrm{mM})$ and fluorescein $(82.1 \mathrm{nM})$ in $\mathrm{KH}_{2} \mathrm{PO}_{4}$ buffer $(100$ $\mathrm{mM}, \mathrm{pH}$ 7.4) were prepared daily. Samples ( $25 \mu \mathrm{L} /$ well) of tested extracts dissolved in buffer containing $0.05 \% \mathrm{v} / \mathrm{v}$ DMSO $(0.94-7.5 \mu \mathrm{g} / \mathrm{mL}$, final concentration) were mixed with 150 $\mu \mathrm{L} /$ well of fluorescein solution and the mixture was incubated for $10 \mathrm{~min}$ at $37^{\circ} \mathrm{C}$. Aliquots of AAPH solution ( $25 \mu \mathrm{L} /$ well, $19.12 \mathrm{mM}$, final concentration) were added and the fluorescence was recorded at 2-min intervals for 70 min at wavelengths of $485 \mathrm{~nm}$ for excitation and $530 \mathrm{~nm}$ for emission. Blank was made using PBS instead of test fraction. In each assay a calibration curve was performed with Trolox $(0.4-12.5 \mu \mathrm{M})$ as standard. The ORAC values were calculated using the neat AUCs and expressed either as $\mu$ mole TE per gram of extract weight or TE (standards).

\subsubsection{Xanthine oxidase inhibition assay}

Inhibition of XO by the extracts was evaluated in microplates by measuring the inhibition of XO-catalyzed formation of uric acid from xanthine as described previously (Cos et al., 1998). Samples ( $150 \mu \mathrm{L} /$ well) dissolved in DMSO (18.5-600 $\mu \mathrm{g} / \mathrm{mL}$, final concentration) were added to $250 \mu \mathrm{L} /$ well of a reaction mixture consisting of $25 \mu \mathrm{L}$ xanthine solution at $50 \mu \mathrm{M}$ and $25 \mu \mathrm{L}$ EDTA solution at $10 \mu \mathrm{M}$, both in PBS $(0.2 \mathrm{M}, \mathrm{pH} 7.5)$ containing $0.31 \% \mathrm{v} / \mathrm{v}$ DMSO. The reaction was started by adding to the mixtures $25 \mu \mathrm{L} /$ well of XO solution $(23.3 \mathrm{mU})$ in PBS. After 30 min incubation at $37^{\circ} \mathrm{C}$ uric acid formation was measured at $290 \mathrm{~nm}$. Enzyme was omitted in the blank controls and $\mathrm{EC}_{50}$ values (in $\mu \mathrm{g} / \mathrm{mL}$ ) were determined as the concentration that halved uric acid formation in the control. Allopurinol and quercetin were used as standards. 


\subsubsection{Superoxide radical scavenging $\left(\mathrm{O}_{2}{ }^{\circ}\right)$ capacity}

The $\mathrm{O}_{2}{ }^{\circ-}$ scavenging capacities were assayed in glycine buffer $(6.25 \mathrm{mM}, \mathrm{pH} 10.1)$ at $25^{\circ} \mathrm{C}$ according to previous procedures (Cassien et al., 2016). The assay measures inhibition by the extracts of lucigenin-derived chemiluminescence produced by the allopurinol/ $\mathrm{XO} \mathrm{O}_{2}{ }^{-{ }^{-}}$generating system. Samples (2.4-48 $\mu \mathrm{L})$ dissolved in glycine buffer:DMSO (1000:1 v/v) at $200 \mu \mathrm{g} / \mathrm{mL}$ were diluted in glycine buffer as to reach a final volume of $1.7 \mathrm{~mL}$. To these solutions were added $300 \mu \mathrm{L}$ of allopurinol solution $(12.5 \mu \mathrm{M})$ and $100 \mu \mathrm{L}$ of $\mathrm{XO}$ solution $(0.458 \mathrm{mU} / \mathrm{mL})$, both in glycine buffer. The test tube was shaken, inserted in a luminometer, $300 \mu \mathrm{L}$ of lucigenin solution in glycine buffer $(2.5 \mu \mathrm{M})$ was added and luminescence of the sample was monitored at 1.2-s intervals for a total period of $4.12 \mathrm{~min}$ following lucigenin addition. The $\mathrm{O}_{2}{ }^{*-}$ scavenging activity was calculated against controls (in the absence of extract) from AUCs. The results are expressed as $\mathrm{IC}_{50}$ values (in $\mu \mathrm{g} / \mathrm{mL}$ ).

\subsubsection{Metal chelating capacity (MCC)}

The MCC of the extracts was measured in microplates according to a published method (Ambigaipalan et al., 2016) with some modification. Samples (200 $\mu \mathrm{L} /$ well) dissolved in methanol at $0.3-2.4 \mathrm{mg} / \mathrm{mL}$ were mixed with $10 \mu \mathrm{L} /$ well of aqueous ferrous chloride ( $2 \mathrm{mM}$ ). The mixture was then reacted with $40 \mu \mathrm{L} /$ well of $5 \mathrm{mM}$ aqueous 3-(2-pyridyl)-5,6-bis(4phenylsulfonic acid)-1,2,4-triazine (ferrozine; Sigma-Aldrich) for $10 \mathrm{~min}$ at room temperature under vigorous stirring. The absorbance was read at $562 \mathrm{~nm}$ and a calibration curve was constructed using EDTA as standard. Percent inhibition of $\mathrm{Fe}^{2+}$-ferrozine complex was calculated using eq 1 where $A_{0}$ is the absorbance of the control (water instead of extract). The results are expressed as micromoles of EDTA equivalents (EDTAE) per gram of extract weight.

\subsubsection{Inhibition of deoxyribose degradation}

The ability of AQL, butanol extract and AR fraction to inhibit the formation of TBA reactive substances resulting from the degradation of deoxyribose by Fenton-derived hydroxyl radical $\left(\mathrm{HO}^{\circ}\right)$ was evaluated in a colorimetric assay according to a reported method (Bailey et al., 2014). When ferrous ions (formed by reducing $\mathrm{Fe}^{3+}$ by ascorbate) are used in the Fenton reagent, adding 
an excess EDTA in the system allows determining the direct $\mathrm{HO}^{\bullet}$ scavenging effect of the extract (radiomimetic assay) while omitting EDTA in the mixture will measure the capacity of the fraction to interact with site-specific $\mathrm{HO}^{\bullet}$-induced damage to deoxyribose (Aruoma et al., 1987; Halliwell et al., 1987). The reaction mixture ( $1 \mathrm{~mL}$, final volume) contained the tested compound $(500 \mu \mathrm{L})$ dissolved in water at $0.025-0.25 \mathrm{mg} / \mathrm{mL}$ and aliquots $(100 \mu \mathrm{L})$ of the following reagents dissolved in $\mathrm{KH}_{2} \mathrm{PO}_{4}$ buffer $(20 \mathrm{mM}$, final concentration; $\mathrm{pH} 7.4)$ : deoxyribose (2.8 $\mathrm{mM}), \mathrm{FeCl}_{3}(100 \mu \mathrm{M})$, EDTA $(100 \mu \mathrm{M})$ or buffer, $\mathrm{H}_{2} \mathrm{O}_{2}(1 \mathrm{mM})$ and ascorbate $(100 \mu \mathrm{M})$. After incubating the mixtures for $1 \mathrm{~h}$ at $37^{\circ} \mathrm{C}$ TBA $(0.5 \mathrm{~mL}, 1 \% \mathrm{v} / \mathrm{v}$ in $50 \mathrm{mM} \mathrm{NaOH})$ and acetic acid $(0.5 \mathrm{~mL})$ were added and the mixture was heated at $100{ }^{\circ} \mathrm{C}$ for $15 \mathrm{~min}$. After cooling, absorbance was read at $532 \mathrm{~nm}\left(\mathrm{~A}_{532}\right)$ against a corresponding blank not containing $\mathrm{FeCl}_{3}$. Mannitol (1-10 $\mathrm{mM}$ ) was used as the reference. Percent inhibition of deoxyribose degradation by the extract in the presence or absence of EDTA was calculated using eq 1 where $A_{0}$ is the absorbance of the control (buffer instead of fraction) and $A$ is the absorbance in the presence of a given concentration of the compound. Control assays in which deoxyribose or Fenton reagents were omitted, or test extracts were added after incubating deoxyribose with the Fenton reagents, but before addition TBA showed no interference with the assay.

\subsubsection{Electron paramagnetic resonance (EPR) spin-trapping analysis}

Using EPR spectrometry following reported procedures (Alencar et al., 2009; Bailey et al., 2014), $\mathrm{HO}^{\bullet}$ scavenging activity of selected extracts was determined by measuring the dosedependent inhibition of its DMPO spin adduct at room temperature. Aliquots of tested extracts (0.01-10 mg/mL, final concentration) dissolved in $\mathrm{KH}_{2} \mathrm{PO}_{4}$ buffer (20 mM; $\left.\mathrm{pH} 7.4\right)$ containing DTPA $(1 \mathrm{mM})$ and DMPO $(5 \mathrm{mM})$ were incubated for $80 \mathrm{~s}$ with a mixture of $\mathrm{H}_{2} \mathrm{O}_{2}(0.5 \mathrm{mM})$ and $\mathrm{FeSO}_{4}(0.5 \mathrm{mM})$. Samples were immediately placed into glass capillaries and X-band (9.81 $\mathrm{GHz}$ ) EPR spectra were recorded on a Bruker ESP 300 instrument (Karlsruhe, Germany) using the following parameters: modulation frequency, $100 \mathrm{kHz}$; micro-wave power, $10 \mathrm{~mW}$; sweep width, $0.07 \mathrm{mT}$; field axis resolution, 2048 points; receiver gain, $8 \times 10^{3}$; modulation amplitude, $0.05 \mathrm{mT}$; time constant, $5.12 \mathrm{~ms}$ and scan rate, $0.33 \mathrm{mT} / \mathrm{s}$. The EPR signal intensities $I$ and $I_{0}$ (buffer instead of test fraction) were quantitated by double integration of the simulated spectra as described (Bailey et al., 2014). Additionally, the relative scavenging rate constants were 
estimated by comparing the slopes of $I_{0} / I$ against concentration linear regression curves according to a previous method (Finkelstein et al., 1980).

\subsection{Inhibition of carbohydrate hydrolyzing enzymes}

All assays described below were carried out starting from stock solutions at $200 \mathrm{mg} / \mathrm{mL}$ dissolved in pure distilled water (AQL and AR fraction) or in the presence of $4 \% \mathrm{v} / \mathrm{v}$ DMSO (other extracts). In the latter case the final DMSO concentration in the tested samples was $<1 \%$ and did not interfere with the assay (not shown). Porcine pancreatic $\alpha$-amylase (EC 3.2.1.1, type VI-B), $\alpha$-glucosidases from Saccharomyces cerevisiae (SC; EC 3.2.1.20, type I), rat intestinal acetone powder (RIP), 2-chloro-4-nitrophenol- $\alpha$-D-maltotrioside (CNPG3) and $p$-nitrophenyl- $\alpha$ D-glucopyranoside ( $p$ NPG) were purchased from Sigma-Aldrich. Porcine pancreatic $\alpha$-amylase assay was performed in microplates using CNPG3 as substrate as described (Gella et al., 1997) and the two $\alpha$-glucosidases assays were performed in using $p$ NPG as substrate according to Oki et al. (1999) with slight modifications (Supplementary methods).

\subsection{Inhibition of $\mathrm{Cu}^{2+}$-induced $\mathrm{LDL}$ oxidation}

Fresh plasma was derived from normolipidic healthy volunteers after informed consent and LDL was isolated within $1 \mathrm{~h}$ after sample collection to obtain an albumin-free LDL preparation according to Miranda et al. (2000). Inhibition of LDL oxidation by extracts was then assayed in microplates by incubating at $37^{\circ} \mathrm{C}$ LDL solutions (50 $\mu$ g protein per $\mathrm{mL}$ ) in PBS in the presence of $\mathrm{CuSO}_{4}(2 \mu \mathrm{M})$ and extracts dissolved in ethanol as to reach a final concentration ranging 5-50 $\mu \mathrm{g} / \mathrm{mL}$ and a final volume of $0.2 \mathrm{~mL} /$ well. LDL oxidation was measured by continuously monitoring for $6 \mathrm{~h}$ conjugated diene hydroperoxide formation at $234 \mathrm{~nm}$ against appropriate blanks (PBS instead of LDL and cupric sulfate) for background correction. After $6 \mathrm{~h}$ incubation, the content of each well was added to a mixture of trichloroacetic acid and TBA ( $1 \%$ in $0.5 \%$ $\mathrm{NaOH}$ ), the samples were heated at $90^{\circ} \mathrm{C}$ for $20 \mathrm{~min}$, then centrifuged and the amount of thiobarbituric acid-reactive substances (TBARS) was measured at $534 \mathrm{~nm}$ with a microplate reader. 


\subsection{Cell culture and cytotoxicity assays}

The human lung cancer cell line A549 (CCL-185, from ATCC, LGC Standards) and normal human lung fibroblasts (NHLF, from Lonza) were routinely maintained in (DMEM + GlutaMax) and (FBM + FGM), respectively as described (Cassien et al., 2016). After reaching 90\% confluence cells were harvested for subculturing. The cells were trypsinized, seeded in 96-well microplates (density, $2.5 \times 10^{4}$ cells/well) and incubated in humidified atmosphere with $5 \% \mathrm{CO}_{2}$ at $37{ }^{\circ} \mathrm{C}$ to reach around $80 \%$ confluence in appropriate medium. The medium was renewed and cells were exposed for $48 \mathrm{~h}$ in the presence of extracts $(5-500 \mu \mathrm{g} / \mathrm{mL})$ or $0.2 \%$ DMSO in medium. After $48 \mathrm{~h}$ cells were washed two times with PBS 1X (+/+) for cytotoxicity analysis.

Rat pancreatic INS-1E beta-cells were cultivated at $37{ }^{\circ} \mathrm{C}$ and $5 \% \mathrm{CO}_{2}$ in RPMI 1640 medium containing glucose $(11 \mathrm{mM})$, fetal bovine serum $(10 \%)$, glutamine $(2 \mathrm{mM})$, sodium pyruvate $(1 \mathrm{mM})$, HEPES $(10 \mathrm{mM}), \beta$-mercaptoethanol $(0.05 \mathrm{mM})$, penicillin and streptomycin according to procedures previously established (Merglen et al., 2004). Cells were then exposed to medium containing high $(25 \mathrm{mM})$ or normal $(5 \mathrm{mM})$ glucose concentration for $84 \mathrm{~h}$ in 96 -well plates in the presence of extracts $(2-200 \mu \mathrm{g} / \mathrm{mL})$ or $0.1 \%$ DMSO in medium. Medium was renewed every day until analysis of viability, metabolic activity and apoptosis (see below).

Cytotoxicity was evaluated by two complementary assays performed according to described procedures, i.e., a fluorometric microculture cytotoxicity assay (FMCA; see Cassien et al., 2016), and the MTT assay (Culcasi et al., 2012). Intracellular ATP content, an index of metabolic activity, was assayed using a luciferin-luciferase reagent (Biofax $\mathrm{A}^{\circledR}$; Yelen, Ensuès la Redonne, France; http://www.yelen-analytics.com). Apoptosis was evaluated by assaying caspase-3 activity of cell lysates using a commercial fluorescence microplate kit assay (Fischer Scientific, France). These procedures are detailed in the Supplementary methods section.

\subsection{Animals and study design}

Standard diet (SD; $11 \%$ energy by fat) and high-fat diet (HFD, 60\% energy by fat) were purchased from Safe (Augy, France). All diets contained 20\% proteins. Animal care and 
experimental procedures were performed according to the rules of the European Union Council (Revised Directives 2010/63/EU). This protocol was subjected to the scrutinity of the local Animal Research Ethics Committee and was approved for the project FEDER-AdiabaOx (2008, $N^{\circ}$ 13851). Aix Marseille University and the CNRS have a license for animal housing and experimentation (agreement C13-055-06) and the study was under the supervision of a vet at the CNRS. One hundred and twenty-eight 4 weeks-old female C57BL/6J mice were purchased from CERJ (Janvier Labs, Le Genest St Isle, France) and maintained under conventional conditions with controlled temperature $\left(22 \pm 3{ }^{\circ} \mathrm{C}\right)$ and a $12 \mathrm{~h}$ light/dark cycle and access to food and water ad libitum. An enriched environment, by using wheels, tunnels and toys, was given to promote physical and social activity.

After one week acclimatization mice were randomly assigned to three experimental protocols described in the following. A first protocol examined the acute oral toxicity of AQL and butanol extract at $2000 \mathrm{mg} / \mathrm{kg}$ on 16-weeks SD animals ( $n=4 /$ group) according to the procedure of Yamanaka et al. (1990). Extracts, dissolved in a suspension of $0.5 \%$ aqueous carboxymethyl cellulose (as vehicle), were given orally in the limit of $0.1 \mathrm{~mL} / 10 \mathrm{~g}$ body weight. A second protocol consisted of a dose-response study of the acute hypoglycemic activity of the extracts on 16-weeks HFD animals in comparison with glibenclamide ( $n=6 /$ group) as detailed below. In a third series of studies the long-term antidiabetic and antihyperglycemic effects of extracts were evaluated on the remaining 84 mice which were randomly divided into six experimental groups $(n=12)$ : controls given SD for 28 weeks, HFD group (given HFD for 28 weeks), [HFD+AQL] group, given HFD for 16 weeks, followed by HFD supplemented with AQL (150 mg/kg) for 12 weeks; [HFD+AQL 75$]$ group, given HFD for 16 weeks, followed by HFD supplemented with AQL $(75 \mathrm{mg} / \mathrm{kg}$ ) for 12 weeks; [HFD+n-BuOH] group, given HFD for 16 weeks, followed by HDF supplemented with butanol extract $(150 \mathrm{mg} / \mathrm{kg})$ for 12 weeks; [HFD+ Met] group, given HFD for 16 weeks, followed by HFD supplemented with metformin $(150 \mathrm{mg} / \mathrm{kg})$ for 12 weeks and [HFD+Met $\left.{ }_{75}+\mathrm{AQL}_{75}\right]$ group, given HFD for 16 weeks, followed by HFD supplemented with a mixture of metformin and AQL (both at $75 \mathrm{mg} / \mathrm{kg}$ ) for 12 weeks. Weekly weights measurements and daily estimates of food intake and clinical signs of suffering, weight loss and moribundity were recorded. At weeks 16 (before incorporation of extracts in the food) and 28, blood samples were collected from tail vein under local anaesthesia induced by 
$0.25 \%$ lidocaine application in ointment. Blood glucose concentration was measured using a commercial whole-blood glucose auto analyser (Freestyle Optium Neo, Abbott).

\subsection{Acute hypoglycemic activity of extracts}

In this series of experiments single doses of AQL or butanol extract $(25,75,150$ and 250 $\mathrm{mg} / \mathrm{kg}$ ), or glibenclamide (15 mg/kg) dissolved in vehicle (see above) were given orally through a thin flexible cannula. Glucose concentration was monitored in blood samples $(5 \mu \mathrm{L})$ collected from tail vein at $0,0.5,1,3$ and $4 \mathrm{~h}$ after administration. Blood glucose concentration was measured by a commercial whole-blood glucose auto-analyzer.

\subsection{Oral glucose tolerance test (OGTT) in long term-treated mice}

At the end of 28 weeks treatments, the OGTT was performed on $n=6$ animals/group fasted for $8 \mathrm{~h}$ beforehand. A thin cannula was inserted orally and allowed the administration to each animal of $3 \mathrm{~g} / \mathrm{kg}$ glucose solution ( $20 \% \mathrm{w} / \mathrm{v}$ in normal saline solution, Laboratoire Lavoisier, France) in the limit of $0.1 \mathrm{~mL} / 10 \mathrm{~g}$ body weight. Tail blood $(6 \mu \mathrm{L})$ was collected at 0 , 20, 40, 60, 90 and 120 min after $0.25 \%$ lidocaine application in ointment. Blood glucose concentration was measured, a curve over time was generated and the AUC was calculated.

Following the OGTT study, mice were maintained on their respective diets for five additional days, then fasted overnight and deeply anesthetized using sevoflurane (2-4\%) delivered with a mixture $\mathrm{O}_{2} /$ air in an anaesthetic chamber (Abbott, Rungis, France) prior to sacrifice by cervical dislocation.

Blood was withdrawn by orbital cardiac puncture and immediately assayed for reduced glutathione (GSH) and oxidized glutathione (GSSG) levels using a commercial glutathione assay kit (Caymann Chemical, Bertin Pharma, France). Samples of blood hemolyzates were used for hemoglobin $(\mathrm{Hb})$ and glycosylated hemoglobin $\left(\mathrm{HbA}_{1 \mathrm{C}}\right.$, expressed as percentage of total $\mathrm{Hb}$ content) determination as described (Dey et al., 2015). Plasma samples were isolated by centrifugation ( $1650 \mathrm{~g}$ for $15 \mathrm{~min}$ at $3{ }^{\circ} \mathrm{C}$ ) and stored at $-80{ }^{\circ} \mathrm{C}$ for further analysis of glucose and 
insulin levels, and for assaying protein carbonyls and inflammatory markers (see below). Tissues and organs were rapidly dissected out, washed with saline and stored at $-80{ }^{\circ} \mathrm{C}$ for further analysis.

\subsection{Plasma glucose, insulin and lipid metabolism, and protein carbonyls assay}

Plasma concentrations of total proteins, triglycerides, total cholesterol and glucose were assayed using commercially available assay kits (Biolabo Reagents, Maisy, France). Plasma insulin concentrations were measured in blood collected on EDTA using a mouse insulin enzyme immunoassay kit (SPI bio, Bertin Pharma, France). Glycogen and triglyceride contents were assayed in liver tissues using commercial assay kits (Caymann Chemical). Plasma protein carbonyls were assayed using a fluorimetric method based on derivatization with 7-hydrazino-4nitrobenzo-2,1,3-oxadiazole (NBDH; Sigma-Aldrich) according to Stocker et al. (2015). For details see the Supplementary methods section

\subsection{Inflammatory biomarkers}

The plasma levels of leptin, and cytokines interleukin-6 (IL-6), monocyte-chemoattractant protein 1 (MCP-1) and tumor necrosis factor- $\alpha$ (TNF- $\alpha)$ were determined by commercial multiplex assay kit (RECYTMAG-65K; Milliplex Map, Merck, France) on a Magpix unit coupled to a XPONENT 4 software (Luminex Corporation) at the CIPHE (Centre de Luminy, Marseille). Plasma samples on EDTA were diluted with the kit solution after two freeze/thaw cycles $(1: 1 \mathrm{v} / \mathrm{v})$. Determination of biomarkers concentrations $(\mathrm{pg} / \mathrm{mL})$ were drawn from experimental curves reporting mean fluorescence intensity (MFI) as a function of concentration.

\subsection{NADPH oxidase activity in heart ventricular and sketetal muscle}

NADPH oxidase-triggered $\mathrm{O}_{2}{ }^{\bullet-}$ production in heart ventricular and skeletal muscle tissue was monitored by chemiluminescence in presence of NADPH according to Yokota et al. (2009). Briefly, freshly excised heart and hindlimb muscle tissue were snap-frozen with liquid $\mathrm{N}_{2}$ and 
homogenized in buffer containing $250 \mathrm{mM}$ sucrose and $10 \mathrm{mM}$ HEPES. After centrifugation $\left(12000 \mathrm{~g}, 10 \mathrm{~min}\right.$ at $\left.3{ }^{\circ} \mathrm{C}\right), 5 \mu \mathrm{L}$ of the lysate was mixed in each well with $200 \mu \mathrm{L}$ buffer containing (in mM): $\mathrm{NaCl}$ (98), $\mathrm{NaHCO}_{3}$ (25), $\mathrm{KCl}$ (4.7), $\mathrm{KH}_{2} \mathrm{PO}_{4}$ (1.5), $\mathrm{MgSO}_{4}$ (1.2), glucose (11) and HEPES-Na (20). Chemiluminescence was monitored after addition of $5 \mu \mathrm{M}$ lucigenin and $100 \mu \mathrm{M}$ NADPH for starting the reaction. In all groups, control experiments were performed in the presence of the cell-permeable $\mathrm{O}_{2}{ }^{--}$scavenger 4,5-dihydroxy-1,3-benzene-disulfonic acid (Tiron, $20 \mathrm{mM}$ ) or the flavoprotein inhibitor diphenyleneiodonium (DPI, $10 \mu \mathrm{M}$ ).

\subsection{Statistical analysis}

Statistical analyses of the data were performed using GraphPad Prism 5 software (La Jolla, CA, USA). The results are presented as mean \pm SD or SEM for the indicated number of independent experiments. Correlations among data from antioxidant assays were calculated using Pearson's correlation $\left(\mathrm{r}^{2}\right)$ coefficients. In biological experiments evaluation of statistical significance was conducted by Mann-Whitney test when appropriate, or one-way analysis of variance (ANOVA) followed, if significant $(P<0.05)$, by a posteriori Newman-Keuls or Tukey's tests. Differences between groups were considered significant when $P<0.05$.

\section{Results and discussion}

\subsection{TPC, TFC and HPLC analysis}

Phenolic compounds are antioxidant phytochemicals with well-documented beneficial health effets (Del Rio et al., 2013) and in desert/steppic plants such as A. radiata they are thought to provide enhanced protection against harsh environmental oxidative stress conditions. To increase the TPC of AQL obtained by lyophilization of a hot water extract of aerial parts of the plant similar to traditional infusion/decoction, a multistep organic extraction procedure first using methanol, followed by a three-step partitioning of aqueous phase with PE, ethyl acetate and $n$ butanol was carried out (Fig. 1). The TPC, TFC and TFC/TPC ratio of AQL, methanol extract and its derived fractions are summarized in Table 1 (left panel). The data demonstrated a high 
content of phenolics and flavonoids for AQL and methanol extract that fell in the middle range of values reported for hydroalcoholic extracts of A. radiata (e.g., $57 \mathrm{mg} \mathrm{GAE} / \mathrm{g}$ in Hamada and Ladjel (2015) or 100-200 mg GAE/g in Bammou et al. (2015)), possibly reflecting geographical or seasonal variability, or differences in plant drying procedures. The marginal differences found between aqueous and methanol extracts regarding TPC and TFC are not surprising because these solvents can dissolve almost equally a large portion of polar phenolic compounds (Daneshfar et al., 2008). However using methanol extract as starting material for further fractionation was considered more pertinent since it significantly favoured the recovery of flavonoids, i.e., a 40-75\% increase in the TFC/TPC ratio across extracts was recorded (Table 1, left panel). As expected, the ethyl acetate and butanol extracts showed the highest TPC and TFC compared to the methanol extract. Recently, using a similar water partition procedure with ethyl acetate and $n$-butanol led to optimized TPC from hexane extracts of Rhododendron anthopogonoides (Jing et al., 2015). Owing to the weakest TPC and TFC recovered in the PE and AR fractions, the results indicated that the total phenolics of the aerial parts of $A$. radiata could be enriched in the hydroalcoholic and ethyl acetate fractions. 


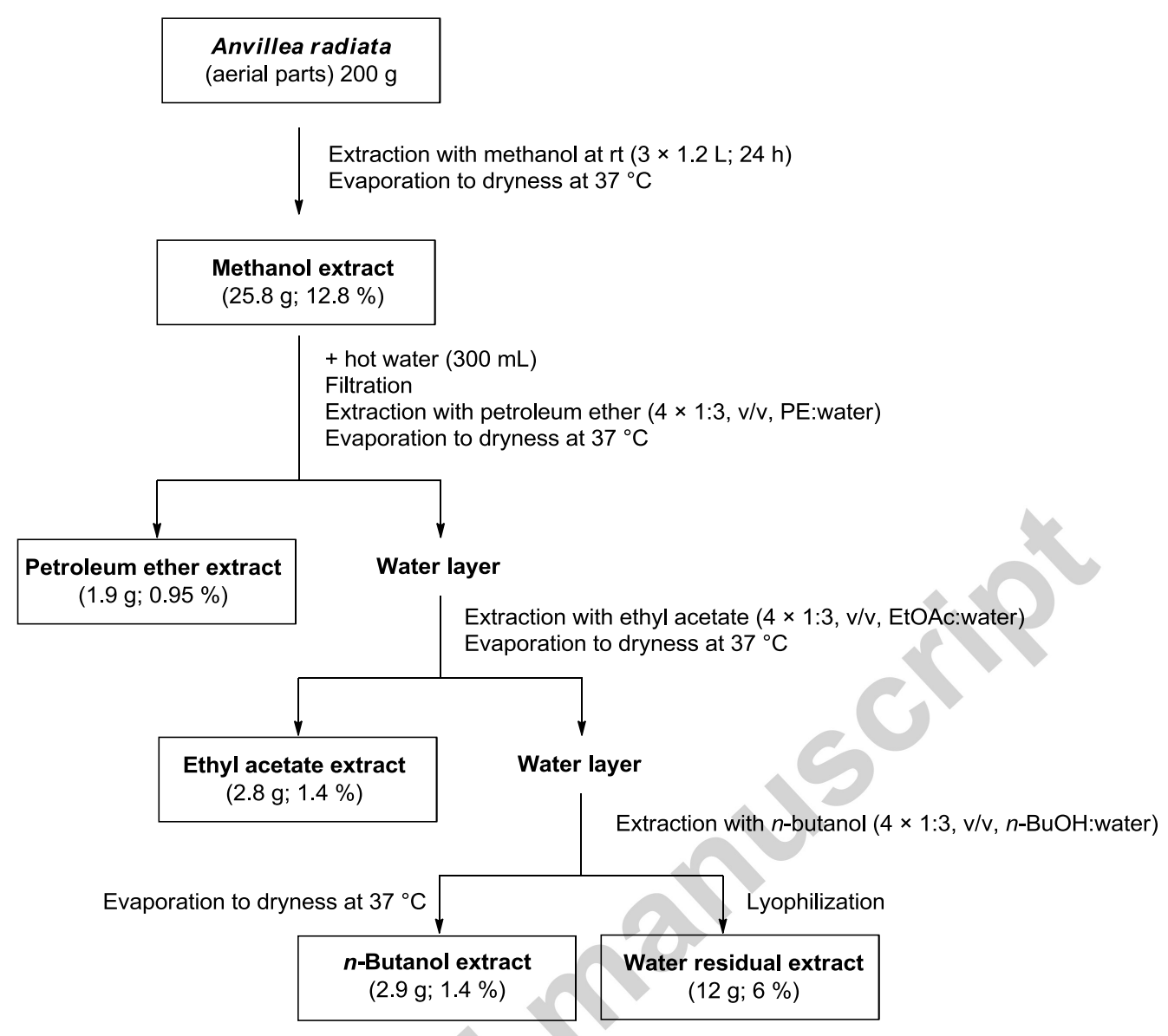

Fig. 1. Preparation of organic extracts of Anvillea radiata.

As the TPC and TFC were determined further, identification and quantitation of the phenolics profile in the six A. radiata extracts was carried out by HPLC using a diode array detector (DAD). Representative chromatograms are displayed in Fig. 2. The qualitative-quantitative analysis of each extract is presented in Table 1 (right panel). Hydroxycinnamic derivatives and flavonoids, which were present in significant amounts in ethyl acetate and butanol extracts with yet a quite different range of compounds (Fig. 2), were still found in good yields in the starting AQL and methanol extract, while they were recovered in weak amounts or even traces in the PE and residual AR fractions. According to their higher polarity, hydroxybenzoic derivatives appeared as minor constituents in hydroalcoholic extracts. These classes of phenolics were readily identified by comparison with the retention times $\left(t_{\mathrm{R}}\right)$ and UV spectra of authentic standard samples of gallic $\left(t_{\mathrm{R}}=4.2 \mathrm{~min}\right)$ and caffeic $\left(t_{\mathrm{R}}=13.4 \mathrm{~min}\right)$ 
acids, and rutin $\left(t_{\mathrm{R}}=28.2 \mathrm{~min}\right)$ at maximal absorption wavelengths of 280,320 and $350 \mathrm{~nm}$, respectively.
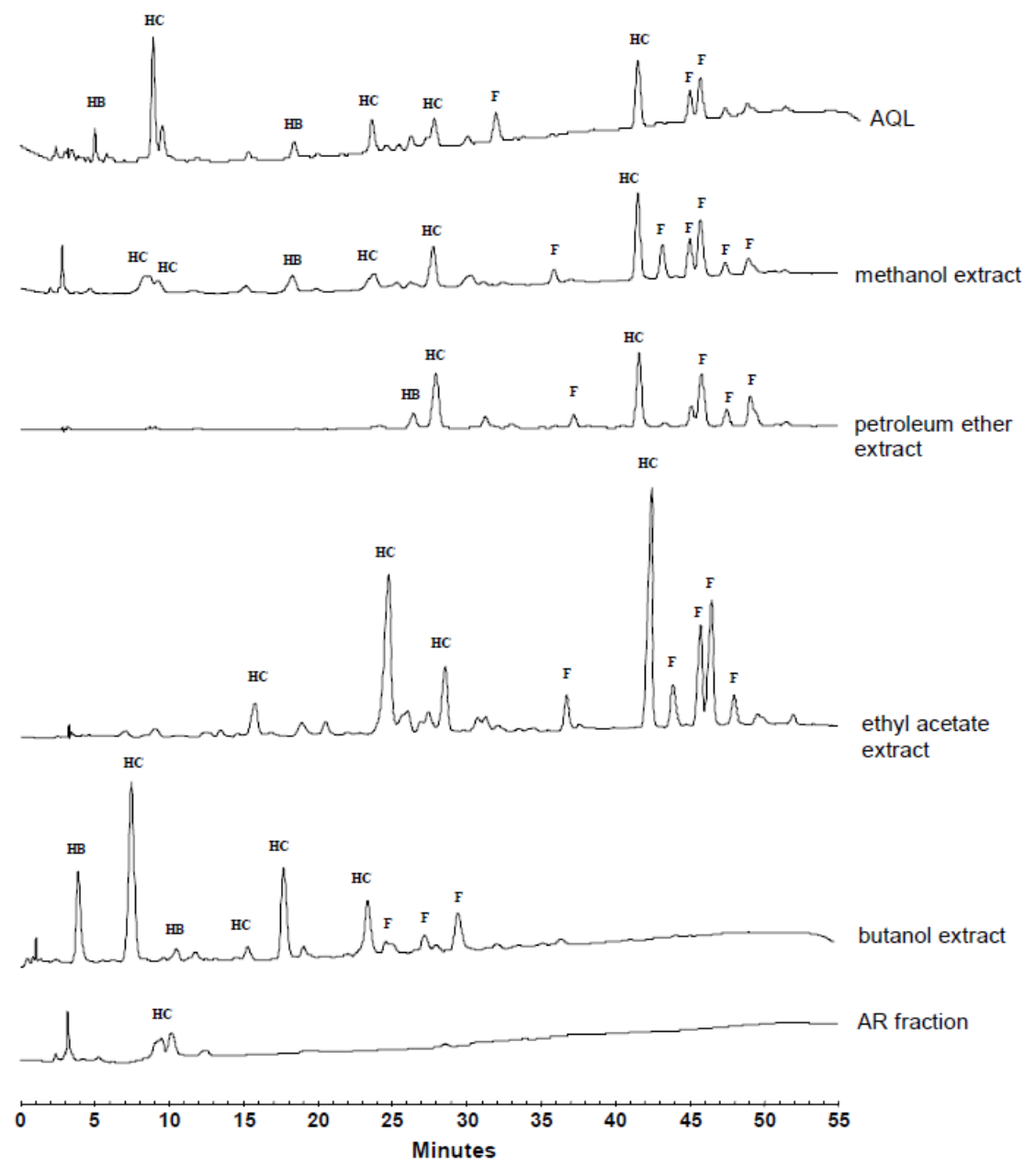

Fig. 2. HPLC-DAD chromatograms of A. radiata phenolic compounds detected at $280 \mathrm{~nm}$ in various extracts: AQL, lyophilized aqueous extract; AR, aqueous residual. Peak labels: HB, benzoic acid derivatives; HC, hydroxycinnamic acid derivatives; F, flavonoids derivatives.

AQL and methanol extract showed close HPLC-DAD profiles, only differing by some extra flavonoids. The efficiency of the fractionation scheme of $A$. radiata (Fig. 1) is illustrated by the fact that the AR fraction contained only traces of hydroxycinnamic derivatives (Fig. 2). Moreover, the butanol fraction retained a flavonoids content of $\sim 40 \mathrm{mg} \mathrm{RUE} / \mathrm{g}$, corresponding to that reported by Dendougui et al. (2006) who extracted similar quantity of $A$. radiata dried material using methanol. Among the phytochemicals contents, strong correlations were obtained 
between the TPC and hydroxycinnamic derivatives $\left(\mathrm{r}^{2}=0.956, P<0.001\right)$ or flavonoids $\left(\mathrm{r}^{2}=\right.$ $0.892, P<0.01)$, whereas hydroxybenzoic compounds did not correlate $(P>0.05)$.

\subsection{In vitro antioxidant properties}

Antioxidant activity of extracts was evaluated by a series of assays that differ in their endpoints, i.e., the mechanisms implicated and/or targets.

\subsubsection{DPPH, ORAC and TRAP}

The results of the DPPH (performed in methanol and globally measuring free radical reducing activity (Ambigaipalan et al., 2016; Foti, 2015) ORAC and TRAP (both performed in buffer and measuring scavenging of peroxyl radicals) assays are shown in Table 2. In the DPPH assay, where a lower $\mathrm{IC}_{50}$ value indicates increased activity, ethyl acetate and butanol extracts exhibited the highest activity $\left(\mathrm{IC}_{50} \sim 45 \mu \mathrm{g} / \mathrm{mL}\right.$ ). The AR fraction and PE extract were 5-10 times less potent and the standard antidiabetic drug metformin was found inactive $\left(\mathrm{IC}_{50}>500 \mu \mathrm{g} / \mathrm{mL}\right)$. Such a higher DPPH scavenging effect for ethyl acetate and butanol vs methanol extracts has been already observed (Benhammou et al., 2009; Jing et al., 2015). In comparison with the literature (Bammou et al., 2015), the method developed in the present study for preparing AQL, methanol and ethyl acetate extracts of $A$. radiata significantly improved DPPH scavenging activity. An analysis of the relationship between TPC, TFC and DPPH data indicated good correlations $(P<0.05)$ between these parameters, with Pearson's coefficients $r^{2}=0.672$ for TPC and $\mathrm{r}^{2}=0.678$ for TFC. The phenolic compounds caffeic acid, quercetin and gallic acid exhibited much stronger activities in the DPPH assay, with $\mathrm{IC}_{50}$ values of $4.71 \pm 0.05,1.71 \pm 0.39$ and 1.26 $\pm 0.01 \mu \mathrm{g} / \mathrm{mL}$, respectively. Being a single electron-based reaction with phenoxyl radical intermediates, DPPH quenching is favoured in phenolics featuring catechol (as in caffeic acid and quercetin) or pyrogallol (as in gallic acid) moieties (Alov et al., 2015; Foti, 2015). This could explain the higher activities seen in the ethyl acetate and butanol extracts which are enriched in structurally-related hydroxycinnamic constituents (Table 1 and Fig. 2) having known antioxidant properties (Shahidi and Chandrasekara, 2010). Consistent, a good correlation was found between DPPH data and hydroxycinnamic contents $\left(\mathrm{r}^{2}=0.534, P<0.05\right)$. Finally, $\mathrm{TIC}_{50}$ values were 
determined to characterize the kinetic behavior of the extracts in DPPH scavenging. According to a previous ranking (Sanchez-Moreno et al., 1998), caffeic acid is a rapid scavenger $\left(\mathrm{TIC}_{50}=\right.$ $8.8 \mathrm{~min}$ ), the $\mathrm{AQL}$, ethyl acetate and butanol extracts showed intermediate kinetic properties similar to that of gallic acid $\left(\mathrm{TIC}_{50}=29.8 \mathrm{~min}\right)$, while methanol and PE extracts, and AR fraction were the slowest scavengers, comparable to quercetin ( $\mathrm{TIC}_{50}>60 \mathrm{~min}$ ).

Antioxidant capacity determined by ORAC and TRAP consistently showed significant increase for the ethyl acetate and butanol extracts compared to the initial AQL and methanol extract (Table 2). Highly significant correlations were found between ORAC $\left(\mathrm{r}^{2}=0.950 ; P<\right.$ $0.001)$ or TRAP $\left(\mathrm{r}^{2}=0.821 ; P<0.01\right)$ and the hydroxycinnamic derivatives contents. The correlations remained strong concerning the flavonoids contents, with Pearson's coefficients $\mathrm{r}^{2}=$ $0.893, P<0.01$ for ORAC and $\mathrm{r}^{2}=0.832, P<0.05$ for TRAP. Again, metformin was found not effective in both TRAP and ORAC assays.

\subsubsection{Superoxide radical scavenging and inhibitory effects on prooxidants}

To limit oxidative stress, inhibiting $\mathrm{O}_{2}{ }^{\bullet-}$ and/or some biological sources and conditions of production could be of relevance for the medicinal usage of $A$. radiata. The results of XO inhibition (by measuring uric acid production according to $\mathrm{Cos}$ et al. (1998)), $\mathrm{O}_{2}{ }^{--}$scavenging (by a fluorescence method (Cassien et al., 2016)) and MCC determination (by the ferrozine assay (Ambigaipalan et al., 2016) performed in methanol) are shown in Table 3. Only AQL, methanol, ethyl acetate and butanol extracts demonstrated weak XO inhibitory activities $\left(\mathrm{IC}_{50}>100\right.$ $\mu \mathrm{g} / \mathrm{mL}$ ) compared to fairly strong (allopurinol and quercetin) or moderate (caffeic and gallic acids) inhibitors (see Cassien et al. (2016) for the two latter compounds). Table 3 shows that the same extracts demonstrating appreciable inhibition against $\mathrm{XO}$ possessed much stronger $\mathrm{O}_{2}{ }^{*-}$ scavenging activities (i.e., $\sim 1000$-fold), as indicated by considerably lower $\mathrm{IC}_{50}$ values $<0.3$ $\mu \mathrm{g} / \mathrm{mL}$. Strong positive correlations $(P<0.05)$ were obtained between $\mathrm{O}_{2}{ }^{\circ-}$ quenching and TPC $\left(\mathrm{r}^{2}=0.711\right)$, TFC $\left(\mathrm{r}^{2}=0.776\right)$ and hydroxycinnamic derivatives contents $\left(\mathrm{r}^{2}=0.556\right)$, but not with hydroxybenzoic derivatives, suggesting the participation of phenolics constitutes of the extracts (and particularly hydroxycinnamates). The MCC value, an index of the capacity of compounds to inhibit iron-induced lipid peroxidation by forming complexes with $\mathrm{Fe}^{2+}$, exhibited strong variations among extracts, decreasing in the order: $\mathrm{PE}>\mathrm{AQL} \approx$ methanol $>$ ethyl acetate 
$\approx$ AR fraction $\approx$ butanol (Table 3). Globally, the activities were weak to moderate as compared to reference compounds and negative, but not significant correlations were found between the MCC of extracts and TPC, TFC, or any of the peroxyl (TRAP, ORAC) and $\mathrm{O}_{2}{ }^{--}$radicals scavenging activity indices tested above $\left(r^{2}=0.294-0.464\right)$. Of interest, an inverse correlation was observed between MCC and DPPH reducing activity $\left(\mathrm{r}^{2}=0.657, P<0.05\right)$, in agreement with previous observations (Zhao et al., 2008), suggesting that extracts with higher MCC capacity might have lower scavenging activity. Notably, a negative correlation was found between MCC and HPLCdetermined flavonoid content $(\mathrm{r}=-0.853, P<0.05)$ suggesting that in most of the extracts, flavonoids could be predominantly in a metal-flavonoid complex form, with consequently a poor chelating capacity but increased antioxidant and scavenging properties (Liu et al., 2015), rather as glycoside conjugates.

\subsubsection{Hydroxyl radical scavenging activity of water soluble extracts}

The $\mathrm{HO}^{\bullet}$ inhibitory activity was first determined using a radiomimetic (with EDTA) and site-specific (without EDTA) deoxyribose assay in phosphate buffer, $\mathrm{pH}$ 7.4. All the three water soluble extracts showed concentration-dependent inhibition of deoxyribose oxidative degradation in both conditions, with a peak at $\sim 0.25 \mathrm{mg} / \mathrm{mL}$ and a greater activity observed in the radiomimetic assay (Fig. 3A). The 'free' $\mathrm{HO}^{\bullet}$ scavenging potencies, as can be estimated by radiomimetic assay (Halliwell et al., 1987), decreased among extracts in the following order: butanol $\approx \mathrm{AQL}>\mathrm{AR}$ fraction. The iron chelation potencies, as can be estimated by the sitespecific assay (Aruoma et al., 1987), decreased among extracts in the following order: butanol > $\mathrm{AQL} \approx \mathrm{AR}$ fraction, a discrepancy with the MCC data (Table 3) that could originate from differences in solvent and $\mathrm{pH}$. At a concentration of $0.3 \mathrm{mg} / \mathrm{mL}$ all samples exhibited a marked reincrease of absorbance, especially under radiomimetic conditions (Fig. 3A). Such pro-oxidant effect in the deoxyribose assay is common to several plant-derived polyphenols and flavonoids such as quercetin (Puppo, 1992), and the strong potency seen in the butanol extract may be related to its high TPC and TFC contents (Table 1).

In addition, the relative rate constants for the $\mathrm{HO}^{\bullet}$ scavenging by extracts were estimated by determining the slopes of plots of $1 / A_{532}$ against concentration in the radiomimetic assay (Fig. 
3B). Using that method, a rate constant of $1.9 \times 10^{9} \mathrm{M}^{-1} \cdot \mathrm{s}^{-1}$ was obtained for mannitol, in agreement with literature data (Halliwell et al., 1987). Thus, the calculated apparent rate constants for butanol extract, AQL and AR fraction were of $11.2 \times 10^{9}, 9.5 \times 10^{9}$ and $6.3 \times 10^{9}$ $\mathrm{M}^{-1} \cdot \mathrm{s}^{-1}$, respectively.

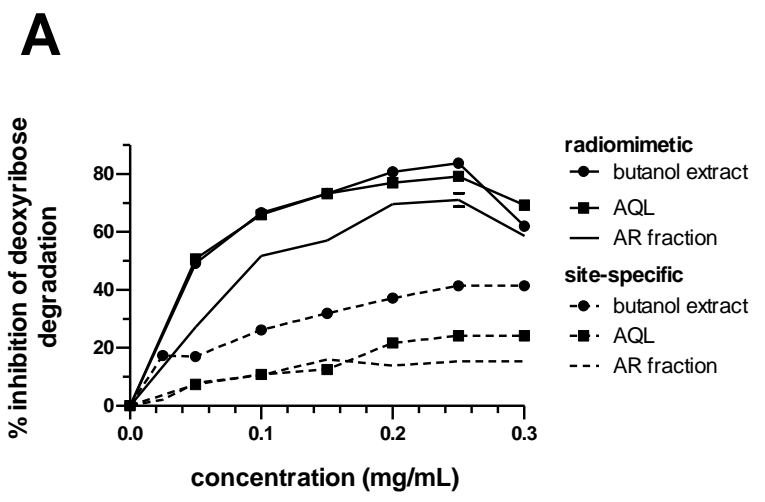

B
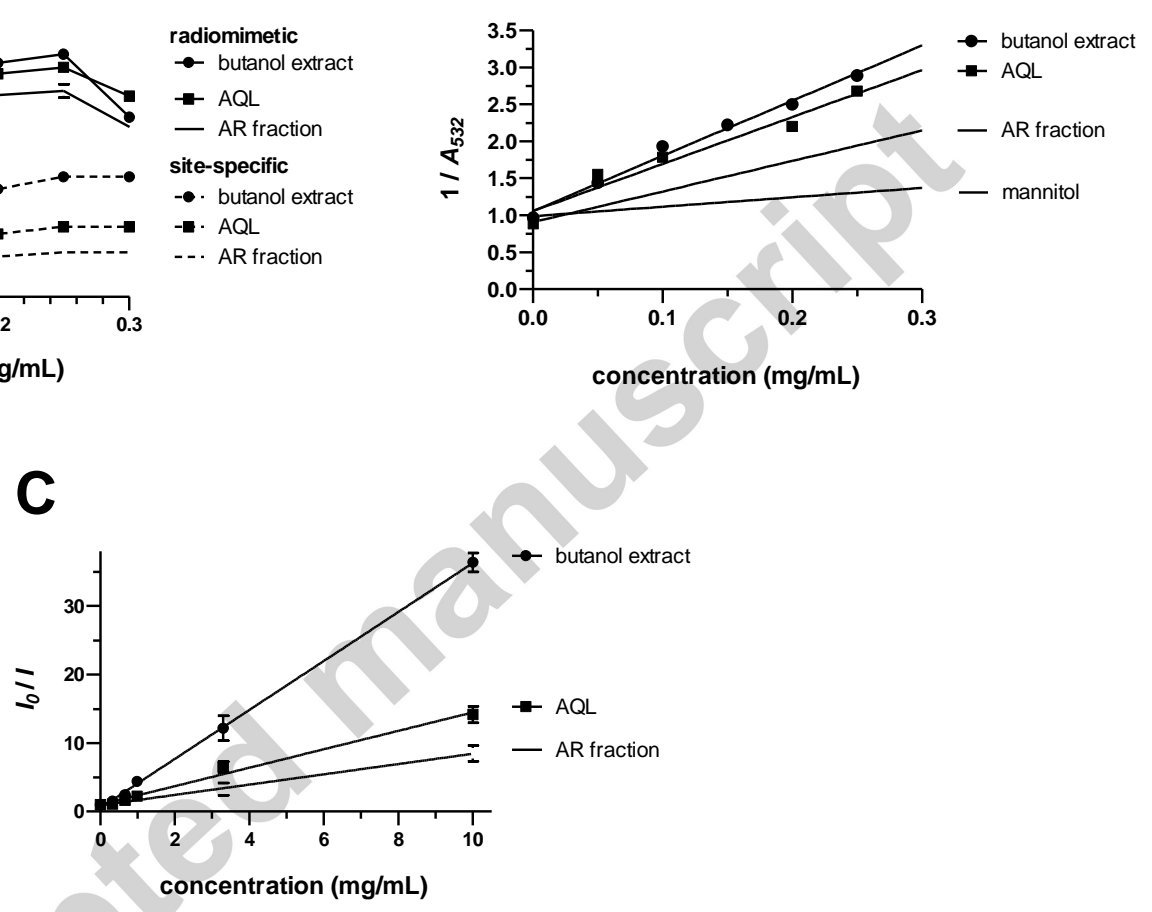

Fig. 3. Hydroxyl radical scavenging by $A$. radiata water soluble extracts. Values represent means \pm SEM $(n=3-6)$. (A) Concentration-dependent effect of extracts on $\left[\mathrm{Fe}^{3+}\right.$-ascorbate $\left.-\mathrm{H}_{2} \mathrm{O}_{2}\right]$ deoxyribose degradation in the presence (radiomimetic) or absence (site-specific) of EDTA. (B) Determination of rate constants for $\mathrm{HO}^{\circ}$ scavenging. Absorbances at $532 \mathrm{~nm}\left(A_{532}\right)$ were that measured in the radiomimetic deoxyribose assay. (C) Kinetic competition plots for the trapping on DMPO of $\left[\mathrm{Fe}^{2+}-\mathrm{H}_{2} \mathrm{O}_{2}\right]$-generated $\mathrm{HO}^{\bullet}$ in the presence of extracts. $I_{0}$ and $I$ represent EPR signal intensities in the extract-free control and sample, respectively.

In a second set of experiments EPR spin-trapping was used as an alternative method to measure $\mathrm{HO}^{\bullet}$ inhibitory activity. Hydroxyl radicals generated in a $\mathrm{Fe}^{2+}-\mathrm{H}_{2} \mathrm{O}_{2}$ system were trapped by the spin trap DMPO to form adducts which can be detected by EPR. The signal is inhibited by $\mathrm{HO}^{\circ}$ scavengers which compete with DMPO for $\mathrm{HO}^{\bullet}$. The results confirmed the 
strong $\mathrm{HO}^{\bullet}$ scavenging activities seen in the deoxyribose radiomimetic assay, with concentration-dependent inhibition of the EPR signals obtained up to $10 \mathrm{mg} / \mathrm{mL}$ for each extract. It must be pointed out that in all experiments with the butanol extract no additional signals were detected, e.g., secondary carbon centered adducts arising from the reaction of $\mathrm{HO}^{\bullet}$ with residual $n$-butanol. Using an established methodology (Finkelstein et al., 1980), the apparent rate constants for $\mathrm{HO}^{\bullet}$ scavenging were estimated from the slopes of the competitive kinetic plots shown in Fig. 3C. Compared to the scavenging potency of the butanol extract, other extracts appeared less efficient in the EPR assay ( $-62 \%$ for AQL and $-79 \%$ for AR fraction) vs the radiomimetic deoxyribose assay ( $-15 \%$ for $\mathrm{AQL}$ and $-44 \%$ for $\mathrm{AR}$ fraction).

\subsection{Inhibitory activities against digestive enzymes}

The management of postprandial blood glucose levels using carbohydrate-hydrolyzing enzymes inhibitors from natural sources is considered an economically attractive therapeutic approach in the treatment of type 2 diabetes since the use of synthetic drugs is often associated with gastrointestinal adverse effects. Most studies on plant extracts or phytoconstituents that may contribute to diabetes treatment have focused on the inhibition of $\alpha$-amylase and $\alpha$-glucosidase, which catalyze carbohydrate digestion into glucose (De Sales et al., 2012; Etxeberria et al., 2012). Several members belonging to the Asteraceae family were proposed as functional antidiabetic agents (Sidhu et al., 2013; Silva et al., 2016), a property associated with the enzyme inhibitory potential of their polyphenolic constituents, particularly flavonoids (Silva et al., 2016).

The inhibitory activities of $A$. radiata extracts against pancreatic $\alpha$-amylase and two sources of $\alpha$-glucosidase (SC and RIP) were evaluated. The inhibitors, voglibose, miglitol and acarbose, and the flavonoids of similar structure, luteolin and myricetin, were used as positive controls. Two assays for $\alpha$-glucosidases were carried out because enzymes from different origins are known to strongly differ in inhibition assays due to their different structure (Oki et al., 1999). Table 4 shows $\mathrm{IC}_{50}$ values and the concentrations of samples associated with the maximum inhibition reached. The $\alpha$-amylase inhibitory activities decreased among extracts in the following order: ethyl acetate $>$ butanol $>$ methanol $\approx \mathrm{AQL}$, while the PE extract and AR fraction were inactive (not shown). Interestingly, a stronger inhibition of $\alpha$-amylase activity was reported for 
ethyl acetate and butanol vs PE extracts of Phyllostachys edulis leaves and the authors concluded that high flavonoids levels contained in polar fractions could act by retarding the enzyme carbohydrate digestion and directly interacting with starch (Yang et al., 2014). The pronounced effects of acarbose and both flavonoids shown in Table 4 were in agreement with previous determinations under similar conditions (Oki et al., 1999; Olaokun et al., 2013; Tadera et al., 2006), and, in connection with the flavonoids constituents of the four active extracts, a good correlation was found between their $\alpha$-amylase inhibitory capacity and their respective TPC $\left(\mathrm{r}^{2}=\right.$ $0.912, P<0.05)$, TFC $\left(\mathrm{r}^{2}=0.973, P<0.01\right)$ and hydroxycinnamic contents $\left(\mathrm{r}^{2}=0.988, P<\right.$ $0.01)$.

The SC and RIP $\alpha$-glucosidase inhibitory activities decreased among extracts in the following order: ethyl acetate $\approx \mathrm{AQL}>$ butanol $>$ methanol, and butanol $>$ ethyl acetate $>\mathrm{AQL}$ $>>$ methanol, respectively (Table 4). In both assays the PE extract and AR fraction were again inactive (not shown). In the $\mathrm{SC}$ assay, no $\mathrm{IC}_{50}$ was found for either active extract, while acarbose and both flavonoids, but not miglitol and voglibose, showed at least two-fold better efficiencies. In the RIP assay, both flavonoids were low $\alpha$-glucosidase inhibitors whereas voglibose, miglitol and acarbose showed stronger properties in line with earlier measurements (Oki et al., 1999). Using a SC assay, Silva et al. (2016) reported a strong $\alpha$-glucosidase SC inhibitory activity for the ethyl acetate extracts of Eremanthus crotonides (Asteraceae) and identified several active polyphenolic constituents such as quercetin, quercetin-3-methyl ether, luteolin, and caffeoylquinic acid $n$-butyl ester derivatives. However in both $\alpha$-glucosidase assays performed in the present study, no correlation was found between the inhibition potency and the TPC and TFC of the extracts.

\subsection{Cytotoxicity studies}

The cytotoxic properties of the four extracts exhibiting the highest activities in antioxidant and enzyme inhibition assays were screened against A549 and NHLF cells by running FMCA and MTT cell viability, and metabolic activity assays. Cells were incubated in DMEM containing $0.2 \%$ DMSO as vehicle for $48 \mathrm{~h}$. Prior to experiments it was checked that addition of $0.2 \%$ DMSO in culture medium did not induce any loss of viability of confluent cells after 
incubation for $48 \mathrm{~h}$ (not shown). Results showed very low cytotoxic effects from AQL and butanol extract, with $\mathrm{IC}_{50}$ values $>250 \mu \mathrm{g} / \mathrm{mL}$ in both cell lines, NHLF being understandably more sensitive (Table 5). Much lesser cell viability was observed for the methanol and ethyl acetate extracts and, for this latter fraction, it can be proposed that cytotoxicity may be related to the presence of low polar constituents such as flavonoid conjugates, alkaloids, saponins or tannins that can interfere with cell membranes at high concentrations.

Altogether, the more soluble AQL and butanol extract, which demonstrated optimized antioxidant, enzyme inhibitory and low cytotoxic properties comparable with metformin (Table 5), were considered suitable for further in vivo testing.

\subsection{Protective effect on $L D L$ oxidation}

Oxidative damage of lipid molecules is one of the initial steps in the development of atherosclerosis and cardiovascular diseases caused by hyperlipidemia and its prevention by antioxidants could be an efficient therapeutic approach. Human LDL was oxidized in vitro by copper ions in the presence of 5-30 $\mu \mathrm{g} / \mathrm{mL}$ of $\mathrm{AQL}$, butanol extract or metformin, and the degree of LDL oxidation was assessed by monitoring the production of conjugated dienes (at 234 $\mathrm{nm}$ ) for $6 \mathrm{~h}$ at $37^{\circ} \mathrm{C}$ and TBARS formation (at $532 \mathrm{~nm}$ ) immediately after incubation. Both extracts, at $5 \mu \mathrm{g} / \mathrm{mL}$, but not metformin, significantly inhibited conjugated diene formation relative to LDL oxidized without extract ( $P<0.05$ by two-way ANOVA), and the kinetic profiles indicated a delayed lag time $(>4 \mathrm{~h}$ ) for maximal diene formation that peaked at $4 \mathrm{~h}$ in the control (Fig. 4A). Relative to the control LDL oxidation TBARS levels were significantly decreased by AQL and butanol extract in a concentration-dependent manner (Fig. 4B), with $\mathrm{IC}_{50}$ values of $7.1 \mu \mathrm{g} / \mathrm{mL}$ and $4.2 \mu \mathrm{g} / \mathrm{mL}$, respectively. In these experiments the flavonoids quercetin $\left(\mathrm{IC}_{50}=0.32 \mu \mathrm{g} / \mathrm{mL}\right)$ and luteolin $\left(\mathrm{IC}_{50}=0.98 \mu \mathrm{g} / \mathrm{mL}\right)$, but not naringenin were more potent inhibitors, in line with literature data (Miranda et al., 2000). Again, metformin was ineffective as antioxidant in reducing LDL oxidation as compared to extracts. 

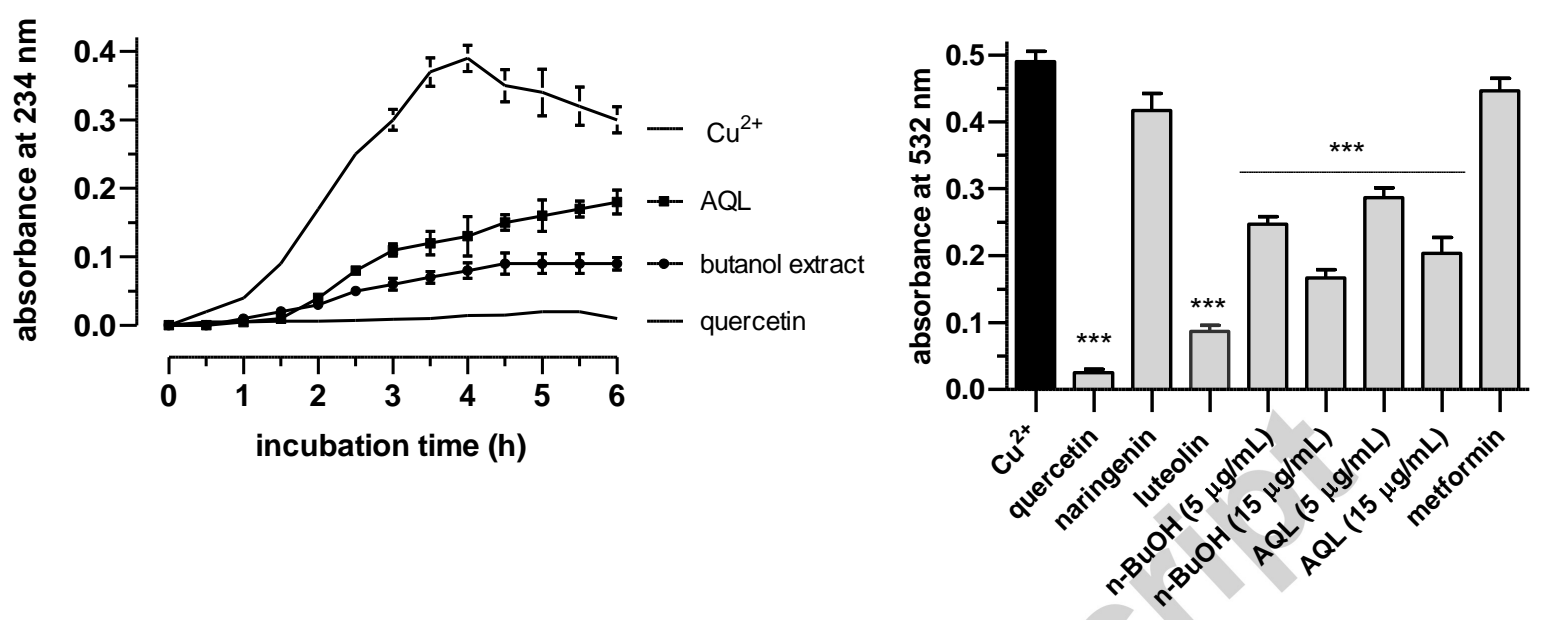

Fig. 4. Oxidation of human LDL ( $50 \mu \mathrm{g}$ proteins $/ \mathrm{mL}$ ) upon incubation with $\mathrm{CuSO}_{4}(2 \mathrm{mM})$ in $\mathrm{PBS}$. (A) Time course of the formation of conjugated dienes in the absence or presence of test compounds ( 5 $\mu \mathrm{g} / \mathrm{mL}$ ). (B) TBARS levels after $6 \mathrm{~h}$ incubation in the absence or presence of test compounds: quercetin and luteolin $(2 \mu \mathrm{g} / \mathrm{mL})$, narigenin $(25 \mu \mathrm{g} / \mathrm{mL})$, metformin $(25 \mu \mathrm{g} / \mathrm{mL})$ or A. radiata extracts (5 or 15 $\mu \mathrm{g} / \mathrm{mL})$. Values represent means $\pm \operatorname{SEM}(n=3-6)$. Statistics: ${ }^{* * *} P<0.001 \mathrm{vs}^{2+}$ (control) by one-way ANOVA followed by multiple comparisons tests.

\subsection{Protective effect on cultured rat pancreatic beta-cells in high-glucose conditions}

It was evaluated whether AQL and butanol extract may promote viability and metabolic activity of rat INS-1E beta-cells exposed to hyperglycemic medium mimicking diabetes conditions. As expected, both cell viability and metabolic activity were significantly reduced to $\sim 50 \%$ of control values when beta-cells were exposed for $84 \mathrm{~h}$ to high glucose (Figs. $5 \mathrm{~A}$ and 5B). Cells exposed to the highest glucose concentration of $25 \mathrm{mM}$ were apoptotic as evidenced by a $\sim 1.5$-fold enhancement of caspase-3 activity vs normal conditions (Fig. 5C).

Hyperglycemia-induced cell damage was dose-dependently prevented by application of 1-15 $\mu \mathrm{g} / \mathrm{mL}$ of each extract (Fig. 5) suggesting that they can be effective as anti-apoptotic and protective agents at doses compatible with plasma concentrations as low as $5 \mu \mathrm{g} / \mathrm{mL}$. Furthermore, these effects of extracts were comparable to that of $3 \mu \mathrm{g} / \mathrm{mL}$ quercetin, suggesting that the phenolic fraction of the extract could be central to the protective activity. 
A

B
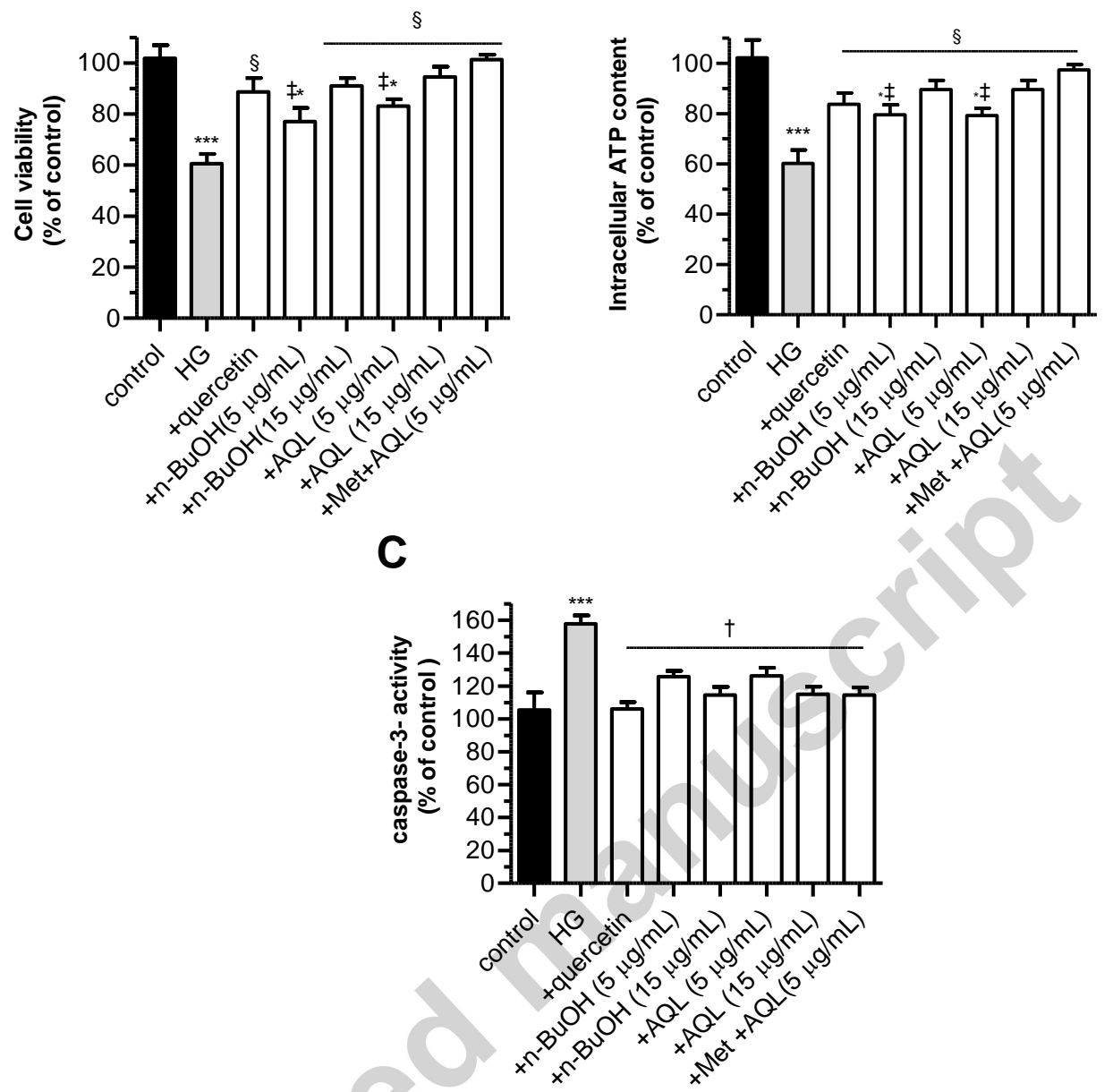

Fig. 5. Protective effect of $A$. radiata extracts against high-glucose induced toxicity in beta-cells. Cell viability and apoptosis were assessed by (A) MTT-based metabolic activity, (B) intracellular ATP content, (C) cytosolic caspase-3 activity. INS-1E cells were incubated in RPMI 1640 medium containing normal glucose (control, $5 \mathrm{mM}$ ) or high-glucose (HG, $25 \mathrm{mM}$ ) concentration for $84 \mathrm{~h}$ in the absence or presence of test compounds: quercetin $(3 \mu \mathrm{g} / \mathrm{mL})$, AQL and butanol extract $(5$ or $15 \mu \mathrm{g} / \mathrm{mL})$ or [Met $+\mathrm{AQL}$ ] (at 2 and $5 \mu \mathrm{g} / \mathrm{mL}$, respectively). Statistics: ${ }^{*} P<0.05$ and ${ }^{* * *} P<0.001$ vs control, ${ }^{\S} P<0.01$ and ${ }^{\dagger} P<0.001$ vs $H G$ and and ${ }^{\sharp} P<0.05$ vs [Met + AQL], by one-way ANOVA followed by Tukey's multiple comparisons tests.

Although data in Tables 2 and 3 are compatible with a poor antioxidative and scavenging property for metformin it yet exerted protective effect on beta-cells at $2 \mu \mathrm{g} / \mathrm{mL}$, possibly by correcting abnormalities of intracellular calcium metabolism in insulin-sensitive tissues (Viollet et al., 2012). Interestingly, adding $5 \mu \mathrm{g} / \mathrm{mL}$ of AQL strongly enhanced this protective effect of metformin on beta-cell survival (Fig. 5). 


\subsection{Acute oral toxicity of extracts on C57BL/6J mice}

Since none of the animals receiving orally $2000 \mathrm{mg} / \mathrm{kg}$ of AQL or butanol extract died up to 10 days, and did not show any signs of pain, distress and suffering, it was considered that the $\mathrm{LD}_{50}$ is $\geq 4000 \mathrm{mg} / \mathrm{kg}$ in both cases. According to Yamanaka et al. (2010), extracts with such low toxicity would not require further testing for lethal effects. Therefore, next pharmacological investigations were carried out using the non toxic dose window of $25-250 \mathrm{mg} / \mathrm{kg}$ of body weight, which is relevant to the use of the plant in traditional medicine (Ghourri et al., 2013).

\subsection{Antidiabetic effect on high-fat-fed C57BL/6J mice}

The potential of plants exerting hypoglycemic and/or insulin mimetic activities to be developed as natural antidiabetics is increasingly exploited. Their biological activity relies on different mechanisms, including inhibition of carbohydrate hydrolyzing enzymes, inhibition of renal glucose reabsorption, insulin secretion stimulation or insulin resistance reduction, increase of the number and the size of cells in the islets of Langerhans, inhibition of glucose production and upregulation of glucose transporters or antioxidant activity (Rios et al., 2015). Although $A$. radiata has been part for a long time of Saharian traditional medicine to treat hyperglycemic related diseases (Bnouham et al., 2006; Hammiche and Maiza, 2006; Ghourri et al, 2013), little is known so far about the usefulness of the plant in treating experimental diabetes. Given the strong antioxidant, radical scavenging, enzyme inhibitory properties and protective activity on lipoproteins and pancreatic cells of $\mathrm{AQL}$ and butanol extract established above, their in vivo potential was investigated in HFD-fed C57BL/6J mice to determine (i) their dose-response acute hypoglycemic activity in blood within $4 \mathrm{~h}$, and (ii) their anti-hyperglycemic and antidiabetic activity after long-term oral treatment,-with the purpose to delineate the underlying mechanisms.

\subsubsection{Acute hypoglycemic activity of extracts: dose determination study}

Mice on HFD for 16 weeks were given the extracts orally at $25,75,150$ and $250 \mathrm{mg} / \mathrm{kg}$ or $15 \mathrm{mg} / \mathrm{kg}$ glibenclamide and blood glucose levels were monitored up to $4 \mathrm{~h}$ post treatment. The 
two extracts showed a potent hypoglycemic property reaching a maximum at $150 \mathrm{mg} / \mathrm{kg}$, with an effect comparable to that of glibenclamide at the dose of $15 \mathrm{mg} / \mathrm{kg}$ (Fig. 6A). Therefore, 150 $\mathrm{mg} / \mathrm{kg}$ was selected for the long term in vivo studies on A. radiata extracts.
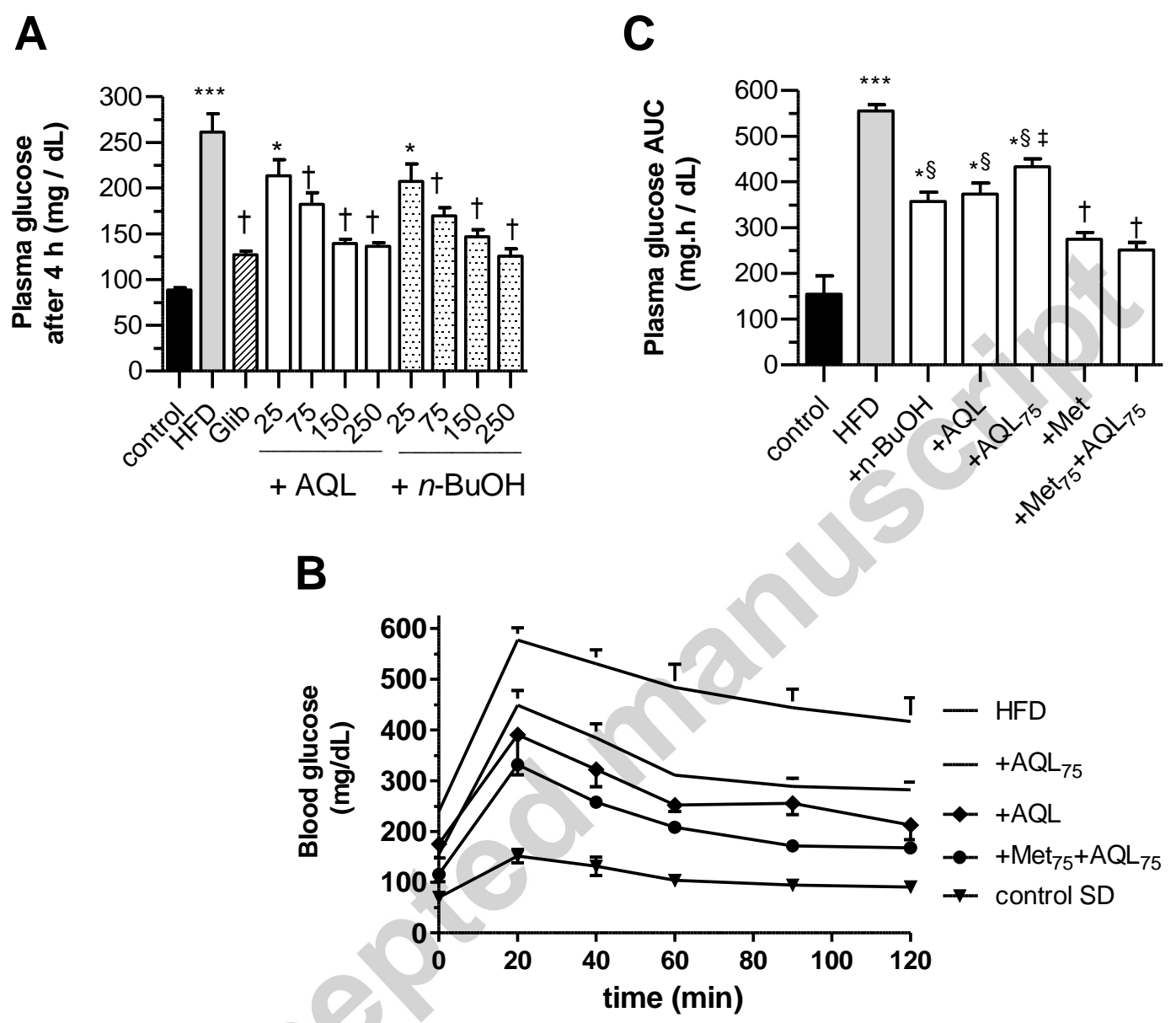

Fig. 6. Acute hypoglycemic effect and oral glucose tolerance test (OGTT) in mice given $A$. radiata extracts. (A) Blood glucose levels after dose-response acute oral treatment (B) Blood glucose levels during OGTT. (C) Area under the curve of blood glucose levels during OGTT. Treatments: control, mice fed with standard diet; HFD, mice on high-fat-diet for 28 weeks; $+n$-BuOH, mice on HFD for 16 weeks, followed by HFD + butanol extract $(150 \mathrm{mg} / \mathrm{kg})$ for 12 weeks; +AQL, mice on HFD for 16 weeks, followed by HFD + AQL (150 mg/kg) for 12 weeks; +AQL ${ }_{75}$, mice on HFD for 16 weeks, followed by HFD + AQL (75 mg/kg) for 12 weeks; +Met, mice on HFD for 16 weeks, followed by HFD + metformin $(150 \mathrm{mg} / \mathrm{kg})$ for 12 weeks; $+\mathrm{Met}_{75}+\mathrm{AQL}_{75}$, mice on HFD for 16 weeks, followed by HFD + [metformin + AQL] (both at $75 \mathrm{mg} / \mathrm{kg}$ ) for 12 weeks. Statistics: ${ }^{*} P<0.05,{ }^{* *} P<0.01$ and ${ }^{* * *} P<0.001$ vs control; ${ }^{\circledR} P<$ 0.01 and ${ }^{\dagger} P<0.001$ vs HFD and ${ }^{\ddagger} P<0.05$ vs $\left[\mathrm{Met}_{75}+\mathrm{AQL}_{75}\right]$ group, by one-way ANOVA followed by Tukey's multiple comparisons tests. 


\subsubsection{Long-term study on diabetic mice: food intake, body weight and body fat pad weight}

At the onset of treatments the mean body weight was of $17.1 \pm 1.1 \mathrm{~g}(n=84)$. Table 6 shows that, after 28 weeks, the animals from the HFD group showed significant higher weight gain ( $+242 \%$, corresponding to $0.85 \mathrm{~g} /$ week) compared to the control SD group $(+175 \%$, corresponding to $0.45 \mathrm{~g} /$ week). Once the obesity induction was characterized at 16 weeks, i.e., the mean weights were $30.7 \pm 0.2 \mathrm{~g}$ in the HFD group and $22.5 \pm 0.1 \mathrm{~g}$ in the SD group, five subgroups of animals from the HFD group were distributed into the [HFD+AQL], [HFD+AQL ${ }_{75}$, $[\mathrm{HFD}+n-\mathrm{BuOH}],[\mathrm{HFD}+\mathrm{Met}]$ and $\left[\mathrm{HDF}+\mathrm{Met}_{75}+\mathrm{AQL}_{75}\right]$ groups and were additionally fed 150 $\mathrm{mg} / \mathrm{kg}$ body weight of the corresponding test compound for the remaining 12 weeks with the exception of $\left[\mathrm{HFD}+\mathrm{AQL}_{75}\right]$ and $\left[\mathrm{HDF}+\mathrm{Met}_{75}+\mathrm{AQL}_{75}\right]$ groups where the doses of $\mathrm{AQL}$ and Met were of $75 \mathrm{mg} / \mathrm{kg}$. While in this period the HFD group continued showing higher body weight compared to SD group, the trend was significantly prevented in $150 \mathrm{mg} / \mathrm{kg}$-treated groups, with comparable final weight gains of $+200 \%,+198 \%$ and $+199 \%$ in the [HFD + AQL], [HFD $+n$ $\mathrm{BuOH}]$ and $[\mathrm{HDF}+\mathrm{Met}]$ groups, respectively (corresponding to $\sim 0.65 \mathrm{~g} /$ week in both groups; Table 6). At the lowest dose of $75 \mathrm{mg} / \mathrm{kg}$, AQL still prevented the development of obesity $(+206 \%)$ and adding metformin even improved the weight reduction $(+191 \%$ in the $\left[\mathrm{Met}_{75}+\mathrm{AQL}_{75}\right]$ group). At the end of treatment, the body fat mass percentage was of $10 \%$ in SD group, which strongly increased to $22 \%$ in HFD group, significantly decreased to only $12 \%$ in the $[\mathrm{HFD}+n-\mathrm{BuOH}]$ and $\left[\mathrm{HFD}+\mathrm{Met}_{75}+\mathrm{AQL}_{75}\right]$ groups and remained within $14-16 \%$ in the other treated groups. As no changes among groups were seen concerning food intake (Table 6), the difference in caloric intake in the HFD group (i.e., $\sim 1.5$-fold vs SD group) is likely responsible for the observed gain in body and fat mass. Results in the HFD group were in accordance with previous reports on the susceptibility of the $\mathrm{C} 57 \mathrm{BL} / 6 \mathrm{~J}$ strain to develop hyperglycemia, hyperinsulinemia and obesity when administered HFD containing $30-60 \%$ fat. These characteristics have been reported appropriate to investigations of curative action of traditional medicines in type 2, insulin resistant diabetes (Gallou-Kabani et al., 2007; Yokota et al., 2009; Hamza et al., 2012). Thus, it was concluded that the two tested extracts could significantly lower HFD-induced increase in body weight and adiposity without affecting the caloric intake.

\subsubsection{Effect on blood glucose and insulin, glucose tolerance, hemoglobin glycation, hyperleptinemia and hyperlipidemia}


At the onset of treatments the baseline levels of fasting glucose and insulin were of 80.4$82.6 \mathrm{mg} / \mathrm{dL}$ and $1.2-1.6 \mathrm{ng} / \mathrm{mL}$, respectively, increasing by $\sim 300 \%$ and $\sim 270 \%$, respectively at week 28 in HFD mice. Treatment with AQL or butanol extract at the dose of $150 \mathrm{mg} / \mathrm{kg}$ and, to a lesser extent with $75 \mathrm{mg} / \mathrm{kg}$ of AQL, significantly reduced blood glucose and moderated hyperinsulinemia as compared to the HFD group. Expectedly, the insulin-sensitizing agent metformin showed potent antihyperglycemic properties at $150 \mathrm{mg} / \mathrm{kg}$, with a slightly better, yet not significative hypoglycemic effect vs AQL and butanol extract at the same dose (Table 6). Compared to SD mice, animals on HFD developed type 2 diabetes with characteristics of insulin resistance as indicated by the OGTT assay. The sustained blood glucose level seen at 90 min was significantly reduced by treatment with either AQL alone $(150 \mathrm{mg} / \mathrm{kg})$ or a mixture of metformin and AQL (both at $75 \mathrm{mg} / \mathrm{kg}$ ) in a dose-dependent manner (Fig. 6B). Improvement of the overall glucose exposure in groups supplemented by AQL and butanol extract was evaluated by calculating the AUC which decreased by $34 \%, 33 \%, 22 \%, 48 \%$ and $55 \%$ in the AQL, butanol (both at $150 \mathrm{mg} / \mathrm{kg}$ ), AQL 75 , Met (at $150 \mathrm{mg} / \mathrm{kg}$ ) and [Met $\left.{ }_{75}+\mathrm{AQL}_{75}\right]$ groups, respectively (Fig. 6C).

As shown in Table 6, the $\mathrm{HbA}_{1 \mathrm{C}}$ content of the HFD group is significantly $(P<0.001)$ increased compared to the SD group, as a consequence of long-term high levels of circulating glucose that reacts with hemoglobin and other proteins. All treatments significantly decreased the $\mathrm{HbA}_{1 \mathrm{C}}$ level towards control value, with a better efficacy exhibited by the combination of AQL and metformin (both at $75 \mathrm{mg} / \mathrm{kg}$ ), an effect consistent with the improved property of this mixture in blood glucose and hyperinsulinemia normalization (Fig. 6B and 6C).

Further, data in Table 6 also revealed that treatments significantly improved lipid metabolism and accumulation in diabetic mice. Hyperleptinemia was reduced by $34.8-61.1 \%$, circulating levels of cholesterol and triglycerides decreased by $24.0-41.5 \%$ and $19.6-37.5 \%$, respectively, and triglycerides accumulation in liver tissue were dramatically reduced by 57.9-75.4\%. It is noteworthy that treatments based on AQL or butanol extract both strongly decreased adipose tissue mass and brought cholesterol and triglycerides levels close to normal values, suggesting that they may exert a lipolytic and/or antiadipogenic activity. In medicinal plants, improved anti-obesity and anti-dislipidemia efficacy has been linked to a high content of 
hydroxycinnamic acid derivatives (Alam et al., 2016), a feature of the butanol extract developed here (Table 1).

Last, the liver glycogen content of HFD mice was significantly $(P<0.01)$ depleted compared to the SD group (Table 6), revealing an increase in gluconeogenic enzymes activities due to the altered action of insulin. All treatments and metformin strongly protected liver glycogen loss, a result that could be related to the ability of the antidiabetic drug to reduce hepatic gluconeogenesis, and improve glucose uptake and pancreatic islet cells protection (Viollet et al., 2012). This hypothesis appears confirmed for AQL and butanol extract owing to the results of the study on beta-cells (Fig. 5).

\subsubsection{Oxidative stress markers and inflammatory cytokines levels}

There is a consensus that chronic hyperglycemia in type 2 diabetic subjects induces a cascade of pathological events, including ROS formation, antioxidant consumption, increased lipid peroxidation, protein oxidation and beta-cells dysfunction (Giacco and Brownlee, 2010; Meigs, 2010). Such increased oxidative stress status was detected in the HFD group which demonstrated $\sim 30 \%$ lowered blood GSH/GSSG levels and $\sim 70 \%$ increased formation of plasma protein carbonyls when compared to the SD group. Both $A$. radiata treatments quite completely (for the ratio of reduced to oxidized glutathione) or partly (protein oxidation) restored the normal levels (Table 6), suggesting the involvement of antioxidant mechanisms such as those found in vitro (Tables 2 and 3). Clinical studies reported a good correlation between elevated protein carbonyls levels and poor glycemic control (i.e., when $\mathrm{Hb}_{\mathrm{ACl}}>7$ ), GSH depletion, impaired trace elements status and lipid peroxidation (Whiting et al., 2008). Although $150 \mathrm{mg} / \mathrm{kg}$ of metformin produced substantial reduction in hyperglycemia and $\mathrm{Hb}_{\mathrm{A} 1 \mathrm{c}}$, it did not significantly affect oxidative stress markers as provided by $A$. radiata extracts at the same dose (Table 6). As in the cell study, a synergistic effect of metformin with $75 \mathrm{mg} / \mathrm{kg}$ of AQL led to a normalization of blood GSH/GSSG ratio and protein carbonyls level.

Diabetes-associated oxidative stress adversely affects (i) myocardial function and structure, leading to diabetic cardiomyopathy and heart failure, and (ii) skeletal muscle mitochondrial respiration, causing impaired tolerance to exercise (Yokota et al., 2009; Meigs, 2010). In particular, $\mathrm{O}_{2}{ }^{\bullet-}$ release consecutive to NADPH oxidase activation has been incriminated as a 
trigger of diabetes-induced cardiovascular and skeletal muscle pathophysiology because high levels of glucose, fatty acids or insulin are responsible for mitochondrial damage and impaired contractile capacity in muscle cells (Yokota et al., 2009; Meigs, 2010).

In accordance, the myocardium and hindlimb muscle of mice on HFD for 28 weeks exhibited a strong increase in NADPH oxidase activity as detected by lucigenin luminescence (Fig. 7), which was abolished when tissue was treated with the NADPH inhibitor DPI or $\mathrm{O}_{2}{ }^{-0}$ scavenger Tiron (data not shown). This NADPH-dependent $\mathrm{O}_{2}{ }^{\circ-}$ production in both types of tissues of diabetic animals was strongly limited by treatment with $150 \mathrm{mg} / \mathrm{kg}$ of each extract or metformin, the latter being significantly less active in the myocardium (Fig. 7B). A dosedependent effect was found when the AQL dose was lowered to $75 \mathrm{mg} / \mathrm{kg}$ and again a better overall response was obtained in the $\left[\mathrm{Met}_{75}+\mathrm{AQL}_{75}\right]$ vs $\mathrm{AQL}_{75}$ groups.

A

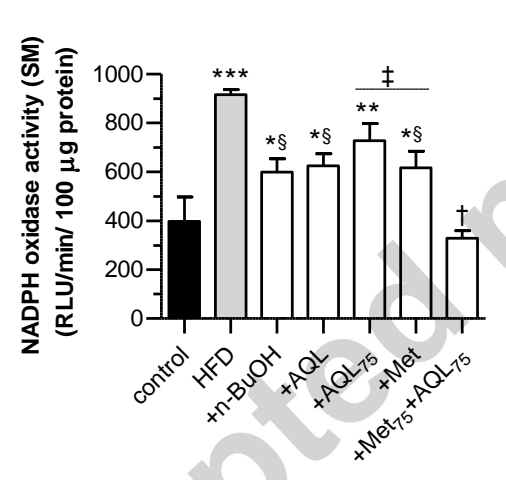

B

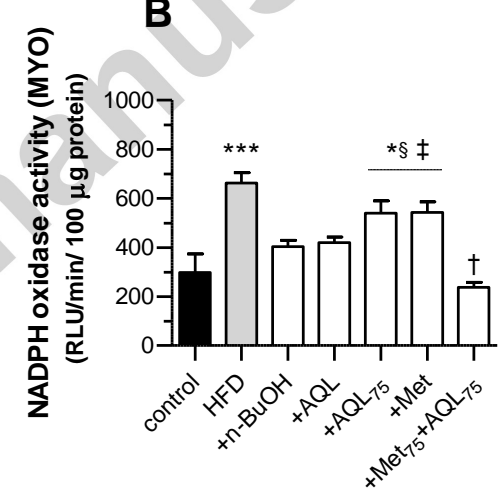

Fig. 7. NADPH oxidase activity in (A) hindlimb skeletal muscle and (B) myocardial homogenates of mice on HFD diet treated with A. radiata extracts. Treatments: see legend of Fig. 6 . Statistics: ${ }^{*} P<0.05$ and ${ }^{* * *} P<0.001$ vs control; ${ }^{\circledR} P<0.01$ and ${ }^{\dagger} P<0.001$ vs HFD and ${ }^{\ddagger} P<0.05$ vs $\left[\mathrm{Met}_{75}+\mathrm{AQL}_{75}\right]$ group, by one-way ANOVA followed by Tukey's multiple comparisons tests.

Another feature of metabolic syndrome associated with obesity is the establishment of a chronic, mild inflammatory state, with the release of inflammatory mediators that could play a crucial role in insulin resistance (Akash et al., 2013). Table 6 shows that both levels of cytokines IL-6 and TNF- $\alpha$, but not MCP-1, were strongly altered in 28 weeks-HFD group mice. Of the tested extracts AQL demonstrated a slightly higher anti-inflammatory activity characterized by a better action on TNF- $\alpha$. Recent studies have reported that plant extracts may serve as dual 
hypoglycemic and anti-inflammatory material (Heyman et al., 2014), or could be used as hypolipidemic treatments possibly acting on cellular pathways involved in adipogenesis expression (Lee et al., 2014).

\section{Conclusion}

In summary, this is the first study to rationalize the traditional use of Anvillea radiata for the treatment of hyperglycemia and diabetic complications. Lyophilized aqueous and butanol extracts of the aerial parts of the plant demonstrated strong antihyperglycemic, antihyperlipidemic and anti-inflammatory activity, and delayed oxidative stress inducedmyocardial and muscle damage C57BL/6J mice selected because they undergo type 2 diabetes similar to humans upon high-fat diet (Fröde and Medeiros, 2008). Since this genetically modified animal model has some limitations, additional in vitro studies were performed to investigate complementary potential molecular mechanisms of action that may support the effectiveness of the plant in humans. Among them, inhibition of $\alpha$-amylase and $\alpha$-glucosidase, antioxidant and free radical scavenging, and protection of pancreatic beta-cells were identified. The two extracts also exhibited strong insulin sensitizing effects comparable to that of metformin. The current results will be useful for assessing the benefit of $A$. radiata extracts in the treatment of diabetic neuropathy, a major complication associated with mitochondrial dysfunction, oxidative stress and inflammatory mediated damage in neurons and glial cells (Sandireddy et al., 2014; Singh et al., 2015). To this purpose, more specific protocols allowing the monitoring of peripheral nerve conduction velocity and injury are available (Yadav et al., 2014; Yang et al., 2015). More generally, it is believed that $A$. radiata-derived material is particularly suitable for developing a neutraceutical for the management of type 2 diabetes and obesity or for add-on therapy with metformin.

\section{Conflict of interest}

The authors have declared no conflict of interest. 


\section{Acknowledgments}

The study was supported by grants from the CNRS and Aix Marseille University. The in vivo part of the study was supported by grants from the FEDER project AdiabaOx (Région PACA, 2008-2012). C.K. gratefully acknowledges the Ministère de l'Enseignement Supérieur et de la Recherche Scientifique (Algérie) for grants (P.N.E. 2014-2016). The authors acknowledge N. Vidal and C. Arzouyan for their valuable assistance.

\section{References}

Akash, M.S., Rehman, K., Chen, S., 2013. Role of inflammatory mechanisms in pathogenesis of type 2 diabetes mellitus. J. Cell. Biochem. 114, 525-531.

Alam, A., Subhan, N., Hossain, M., Reza, H.M., Rahman, M., Ullah, O., 2016.

Hydroxycinnamic acid derivatives: a potential class of natural compounds for the management of lipid metabolism and obesity. Nutr. Metab. 19, 209-215.

Alencar, J., Gosset, G., Rahmouni, H., Culcasi, M., Robin, M., Reynier, J.P., Piccerelle, P., Pietri, S., 2008. Development of spray- and freeze-dried high-concentration sesamol emulsions and antioxidant evaluation in fibroblasts and UV-exposed rat skin slices. Drug Dev. Res. 69, 251-266.

Alencar, J., Gosset, G., Robin, M., Pique, V., Culcasi, M., Mercier, A., Pietri, S., 2009. Improving the stability and antioxidant properties of sesame oil: water-soluble spray-dried emulsions from new transesterified phenolic derivatives. J. Agric. Food Chem. 57, 7311-7323.

Alov, P., Tsakovska, I., Pajeva, I., 2015. Computational studies of free radical-scavenging properties of phenolic compounds. Curr. Top. Med. Chem. 15, 85-104.

Ambigaipalan, P., de Camargo, A.C., Shahidi, F., 2016. Phenolic compounds of pomegranate byproducts (outer skin, mesocarp, divider membrane) and their antioxidant activities. J. Agric. Food Chem. 64, 6584-6604.

Aruoma, O.I., Grootveld, M., Halliwell, B., 1987. The role of iron in ascorbate-dependent deoxyribose degradation. Evidence consistent with a site-specific hydroxyl radical generation caused by iron ions bound to the deoxyribose molecule. J. Inorg. Biochem. 29, 289-299.

Bailey, C.J., Day, C., 1989. Traditional plant medicines as treatments for diabetes. Diabetes Care $12,553-564$. 
Bailey, D.M., Lundby, C., Berg, R.M.G., Taudorf, S., Rahmouni, H., Gutowski, M., Mulholland, C.W., Sullivan, J.L., Swenson, E.R., McEneny, J., Young, I.S., Pedersen, B.K., Moller, K., Pietri, S., Culcasi, M., 2014. On the antioxidant properties of erythropoietin and its association with the oxidative-nitrosative stress response to hypoxia in humans. Acta Physiol. 212, 175-187.

Bammou, M., Sellam, K., El Rhaffari, L., 2015. Bioactivity of Anvillea radiata Coss \& Dur. collected from the southeast of Morocco. European Scientific Journal 11 (21), 233-244.

Benhammou, N., Bekkara, F.A., Panovska, T.K., 2009. Antioxidant activity of methanolic extracts and some bioactive compounds of Atriplex halimus. C. R. Chimie 12, 1259-1266.

Bnouham, M., Ziyyat, A., Mekhfi, H., Tahri, A., Legssyer, A., 2006. Medicinal plants with potential antidiabetic activity. A review of ten years of herbal medicine research (1990-2000). Int. J. Diabetes Metabol. 14, 1-25.

Boudjelal, A., Henchiri, C., Sari, M., Sarri, D., Hendel, N., Benkhaled, A., Ruberto, G., 2013. Herbalist and wild medicinal plants in M'Sila (North Algeria): an ethnopharmacology survey. J. Ethnopharmacol. 148, 395-402.

Boukhris, M.A., Destandau, E., El Hakmaoui, A., El Rhaffari, L., Elfakir, C.A., 2016. Dereplication strategy for the identification of new phenolic compounds from Anvillea radiata (Coss. \& Durieu). C. R. Chimie 19, 1124-1132.

Cassien, M., Petrocchi, C., Thétiot-Laurent, S., Robin, M., Ricquebourg, E., Kandouli, C., Asteian, A., Rockenbauer, A., Mercier, A., Culcasi, M., Pietri, S., 2016. On the vasoprotective mechanisms underlying novel $\beta$-phosphorylated nitrones: Focus on free radical characterization, scavenging and NO-donation in a biological model of oxidative stress. Eur. J. Med. Chem. 25, $197-217$.

Cos, P., Ying, L., Calomme, M., Hu, J.P., Cimanga, K., Van Poel, B., Pieters, L., Vlietinck, A.J., Vanden Berghe, D., 1998. Structure-activity relationship and classification of flavonoids as inhibitors of xanthine oxidase and superoxide scavengers. J. Nat. Prod. 61, 71-76.

Culcasi, M., Benameur, L., Mercier, A., Lucchesi, C., Rahmouni, H., Asteian, A., Casano, G., Botta, A., Kovacic, H., Pietri, S., 2012. ESR spin trapping evaluation of ROS production in human fibroblasts exposed to cerium oxide nanoparticles: evidence for NADPH oxidase and mitochondrial stimulation. Chem. Biol. Interact. 199, 161-176.

Daneshfar, A., Ghaziaskar, H.S., Homayoun, N., 2008. Solubility of gallic acid in methanol, ethanol, water, and ethyl acetate. J. Chem. Eng. Data 53, 776-778.

Dávalos, A., Gómez-Cordovés, C., Bartolomé, B., 2004. Extending applicability of the oxygen radical absorbance capacity (ORAC-fluorescein) assay. J. Agric. Food Chem. 52, 48-54.

Del Rio, D., Rodriguez-Mateos, A., Spencer, J.P.E., Tognolini, M., Borges, G., Crozier, A., 2013. Dietary (poly)phenolics in human health: structures, bioavailability, and evidence of protective effects against chronic diseases. Antioxid. Redox Signal. 18, 1818-1892.

Dendougui, H., Jay, M., Benayache, F., Benayache, S., 2006. Flavonoids from Anvillea radiata Coss. \& Dur. (Asteraceae). Biochem. Syst. Ecol. 34, 718-720. 
De Sales, P.M., Souza, P.M., Simeoni, L.A., Silveira, D., 2012. $\alpha$-Amylase inhibitors: a review of raw material and isolated compounds from plant source. J. Pharm. Pharmaceut. Sci. 15, 14183.

Destandau, E., Boukhris, M.A., Zubrzycki, S., Akssira, M., El Rhaffari, L., Elfakir, C., 2015. Centrifugal partition chromatography elution gradient for isolation of sesquiterpene lactone and flavonoids from Anvillea radiata. J. Chromatogr. B 985, 29-37.

Dey, P., Saha, M.R., Chowdhuri, S.R., Sen, A., Sarkar, M.P., Haldar, B., Chaudhuri, T.K., 2015. Assessment of anti-diabetic activity of an ethnopharmacological plant Nerium oleander through alloxan induced diabetes in mice. J. Ethnopharmacol. 161, 128-137.

Etxeberria, U., de la Garza, A.L., Campión, J., Martínez, J.A., Milagro, F.I., 2012. Antidiabetic effects of natural plant extracts via inhibition of carbohydrate hydrolysis enzymes with emphasis on pancreatic alpha amylase. Exp. Opin. Ther. Targets 16, 269-297.

Fakchich, J., Elachouri, M., 2014. Ethnobotanical survey of medicinal plants used by people in Oriental Morocco to manage various ailments. J. Ethnopharmacol. 154, 76-87.

Finkelstein, E., Rosen, G.M., Rauckman, E.J., 1980. Spin trapping. Kinetics of the reaction of superoxide and hydroxyl radicals with nitrones. J. Am. Chem. Soc. 102, 4994-4999.

Foti, M.C., 2015. Use and abuse of the DPPH• radical. J. Agric. Food Chem. 63, 8765-8776.

Fröde, T.S., Medeiros, Y.S., 2008.Animal models to test drugs with potential antidiabetic activity. J. Ethnopharmacol. 115, 173-183.

Gallou-Kabani, C., Vigé, A.; Gross, M.S., Rabès, J.P., Boileau, C., Larue-Achagiotis, C., Tomé, D., Jais, J.P., Junien, C., 2007. C57BL/6J and A/J mice fed a high-fat diet delineate components of metabolic syndrome. Obesity 15, 1996-2005.

Gella, F.J., Gubern, G., Vidal, R., Canalias, F., 1997. Determination of total and pancreatic alpha-amylase in human serum with 2-chloro-4-nitrophenyl-alpha-D-maltotrioside as substrate. Clin. Chim. Acta 259, 147-160.

Ghourri, M., Zidane, L., Douira, A., 2013. Usage des plantes médicinales dans le traitement du diabète au Sahara marocain (Tan-Tan). J. Anim. Plant Sci., 17, 2388-2411.

Giacco, F., Brownlee, M., 2010. Oxidative stress and diabetic complications. Circ. Res. 107, $1058-1070$.

Gurib-Fakim, A., 2006. Medicinal plants: Traditions of yesterday and drugs of tomorrow. Mol. Asp. Med. 27, 1-93.

Halliwell, B., Gutteridge, J.M.C., Aruoma, O.I., 1987. The deoxyribose method: a simple "testtube" assay for determination of rate constants for reactions of hydroxyl radicals. Anal. Biochem. $165,215-219$. 
Hamada, D., Ladjel, S. 2015. Chemical composition, in-vitro anti-microbial and antioxidant activities of the methanolic extract of Anvillea radiata Asteraceae. Res. J. Pharm. Biol. Chem. Sci. 6, 1367-373.

Hammiche, V., Maiza, K., 2006. Traditional medicine in central Sahara: Pharmacopoeia of Tassili N'ajjer. J. Ethnopharmacol. 105, 358-367.

Hamza, N., Berke, B., Cheze, C., Le Garrec, R., Umar, A., Agli, A.N., Lassalle, R., Jové, J., Gin, H., Moore, N., 2012. Preventive and curative effect of Trigonella foenum-graecum L. seeds in C57BL/6J models of type 2 diabetes induced by high-fat diet. J. Ethnopharmacol. 142, 516-522.

Heyman, L., Axling, U., Blanco, N., Sterner, O., Holm, C., Berger, K., 2014. Evaluation of beneficial metabolic effects of berries in high-fat fed C57BL/6J mice. J. Nutr. Metab. ID403041, $1-12$.

Jing, L., Ma, H., Fan, P., Gao, R., Jia, Z., 2015. Antioxidant potential, total phenolic and total flavonoid contents of Rhododendron anthopogonoides and its protective effect on hypoxiainduced injury in PC12 cells. BMC Complement. Altern. Med. 15, 287, 1-12.

Koleva, I.I., van Beek, T.A., Linssen, J.P., de Groot, A., Evstatieva, L.N., 2002. Screening of plant extracts for antioxidant activity: a comparative study on three testing methods. Phytochem. Anal. 13, 8-17.

Lakhdar, M., Kaid Harche, M., Larbi, B., Sarbani, A., 2013. Phytochemical analysis and antifungal activity of Anvillea radiata. World Appl. Sci. J. 26, 165-171.

Lee, I.S., Kim, D.Y., Choi, B.Y., 2014. Antioxidative activity of blueberry leaf extract prevents high-fat induced obesity in C57BL/6 mice. J. Cancer Prev. 19, 209-215.

Lesgards, J.F., Baldovini, N.,Vidal, N., Pietri, S., 2014. Anticancer activities of essential oils constituents and synergy with conventional therapies: a review. Phytother. Res. 28, 1423-1446.

Liu, Y., Guo, M., 2015. Studies on transition metal-quercetin complexes using electrospray ionization tandem mass spectroscopy. Molecules 20, 8582-8594.

Meigs, J.B., 2010. Epidemiology of type 2 diabetes and cardiovascular disease: translation from population to prevention. Diabetes Care 33, 1865-1871.

Merglen, A., Theander, S., Rubi, B., Chaffard, G., Wollheim, C.B., Maechler, P., 2004. Glucose sensitivity and metabolism-secretion coupling studied during two-years continuous culture in INS-1E insulinoma cells. Endocrinology. 48, 3876-3884.

Miranda, C.L., Stevens, J.F., Ivanov, V., McCall, M., Frei, B., Deinzer, M.L., Buhler D.R., 2000. Antioxidant and prooxidant actions of prenylated and nonprenylated chalcones and flavanones in vitro. J. Agric. Food Chem. 48, 3876-3884.

Moumou, M., El Bouakher, A., Allouchi, H., El Hakmaoui, A., Benharref, A., Mathieu, V., Guillaumet, G., Akssira. M., 2014. Synthesis and biological evaluation of $9 \alpha$ - and $9 \beta$ hydroxyamino-parthenolides as novel anticancer agents. Bioorg. Med. Chem. Lett. 24, 40144018. 
Oki, T., Matsui, T., Osajima, Y., 1999. Inhibitory effect of $\alpha$-glucosidase inhibitors varies according to its origin. J. Agric. Food. Chem. 47, 550-553.

Olaokun, O.O., McGaw, L.J., Eloff, J.N., Naidoo, V., 2013. Evaluation of the inhibition of carbohydrate hydrolysing enzymes, antioxidant activity and polyphenolic content of extracts of ten African Ficus species (Moraceae) used traditionally to treat diabetes. BMC Complement. Altern. Med. 13, 94, 1-10.

Ordonez, A.A.L., Gomez, J.D., Vattuone, M.A., 1sla, M.I., 2006. Antioxidant activities of Sechium edule (Jacq.) Swartz extracts. Food Chem. 97, 452-458.

Pietri, S., Maurelli, E., Drieu, K., Culcasi, M., 1997. Cardioprotective and anti-oxidant effects of the terpenoid constituents of Ginkgo biloba extracts (EGb 761). J. Mol. Cell. Cardiol. 29, 733742 .

Puppo, A., 1992. Effect of flavonoids on hydroxyl radical formation by Fenton-type reactions; influence of the iron chelator. Phytochemistry 31, 85-88.

Rios, J.L., Francini, F., Schinella, G.R., 2015. Natural products for the treatment of type 2 diabetes mellitus. Planta Med. 81, 975-994.

Sanchez-Moreno, C., Larrauri, J.A., Saura-Calixto, F.A., 1998. Procedure to measure the antiradical efficiency of polyphenols. J. Sci. Food Agric. 76, 270-276.

Sandireddy, R., Yerra, V.G., Areti, A., Komirishetty, P., Kumar, A., 2014. Neuroinflammation and oxidative stress in diabetic neuropathy: futuristic strategies based on these targets. Int. J. Endocrinol. 2014 ID 674987,1-10.

Shahidi, F., Chandrasekara, A., 2010. Hydroxycinnamates and their in vitro and in vivo antioxidant activities. Phytochem. Rev. 9, 147-170.

Sidhu, M.C., Sharma, T., 2013. A database of antidiabetic plant species of family Asteraceae, Euphorbiaceae, Fabaceae, Lamiaceae and Moraceae. Int. J. Herb. Med. 2, 187-199.

Silva, E.L., Reveredo Lobo, J.F., Vinther, J.M., Borges, R.M., Staerk, D., 2016. High-resolution $\alpha$-glucosidase inhibition profiling combined with HPLC-HRMS-SPE-NMR for identification of antidiabetic compounds in Eremanthus crotonides (Asteraceae). Molecules 21, 782-793.

Singh, R., Kaur, R., Kishore, L., Gupta, G.K., 2013. Management of diabetic complications: a chemical constituents based approach. J. Ethnopharmacol. 150, 51-70.

Singleton, V.L., Orthofer, R., Lamuela-Raventos, R.M., 1999. Analysis of total phenols and other oxidation substrates and antioxidants by means of Folin-Ciocalteu reagent. Methods Enzymol. 299, 152-178.

Stocker, P., Ricquebourg, E., Vidal, N., Villard, C., Lafitte, D., Sellami, L., Pietri, S., 2015. Fluorimetric screening assay for protein carbonyl evaluation in biological samples. Anal. Biochem. 482, 55-61. 
Tadera, K., Minami, Y., Takamatsu, K., Matsuoka, T., 2006. Inhibition of $\alpha$-glucosidase and $\alpha$ amylase by flavonoids. J. Nutr. Sci. Vitaminol. 52, 149-153.

Viollet, B., Guigas, B., Garcia, N.S., Leclerc, J., Foretz, M., Andreelli, F., 2012.Cellular and molecular mechanisms of metformin: an overview. Clin. Sci. (Lond). 122, 253-270.

Whiting, P.H., Kalansooriya, A., Holbrook, I., Haddad, F., Jennings, P.E., 2008. The relationship between chronic glycaemic control and oxidative stress in type 2 diabetes mellitus. Br. J.

Biomed. Sci. 65, 71-74.

Yadav, S.P., Nagori, B.P., Desai, P.K., 2014. Pharmacological characterization of different fractions of calotropis procera (Asclepiadaceae) in streptozotocin induced experimental model of diabetic neuropathy. J. Ethnopharmacol. 152, 349-357.

Yamanaka, S., Hashimoto, M., Tobe, M., Kobayashi, K., Sekizawa, J., Nishimura, M., 1990. A simple method for screening assessment of acute toxicity of chemicals. Arch. Toxicol. 64, 262268.

Yang, J.P., He, H., Lu, Y.H., 2014. Four flavonoid compounds from Phyllostachys edulis leaf extract retard the digestion of starch and its working mechanisms. J. Agric. Food Chem. 62, 7760-7770.

Yang, X., Yao, W., Li, Q., Liu, H., Shi, H., Gao, Y., Xu, L., 2015. Mechanisms of Tang Luo Ning effect on attenuating of oxidative stress in sciatic nerve of STZ-induced diabetic rats. J. Ethnopharmacol. 174, 1-10.

Yokota, T., Kinugawa, S., Hirabayashi, K., Matsushima, S., Inoue, N., Ohta, Y., Hamaguchi, S., Sobirin, M.A., Ono, T., Suga, T., Kuroda, S., Tanaka, S., Terasaki, F., Okita, K., Tsutsui, H., 2009. Oxidative stress in sketetal muscle impairs mitochondrial respiration and limits exercise capacity in type 2 diabetic mice. Am. J. Physiol. Heart Circ Physiol. 297, H1069-H1077.

Zhao, H., Fan, W., Dong, J., Lu, J., Chen, J., Shan, L., Lin, Y., Kong, W., 2008. Evaluation of antioxidant activities and total phenolic contents of typical malting barley varieties. Food Chem. 107, 296-304.

\section{Glossary}

AAPH, azobis(2-amidinopropane) dihydrochloride; AQL, lyophilized aqueous extract; AR, aqueous residual; CNPG3, 2-chloro-4-nitrophenol- $\alpha$-D-maltotrioside; DMEM, Dulbecco's 
modified Eagle's medium; DMPO, 5,5-dimethyl-1-pyrroline $N$-oxide; DPI, diphenyleneiodonium; DPPH, 2.2-diphenyl-1-picrylhydrazyl; DTPA, diethylenetriaminepentaacetic acid; EPR, electron paramagnetic resonance; FBM, fibroblast basal medium; FGM, fibroblast growth medium; FMCA, fluorometric microculture cytotoxicity assay; GSH, reduced glutathione; GSSG, oxidized glutathione; $\mathrm{Hb}$, hemoglobin; $\mathrm{HbA}_{1 \mathrm{C}}$, glycosylated hemoglobin; HFD, high-fat diet; IL-6, interleukin-6; MCC, metal chelating capacity; MCP-1, monocyte-chemoattractant protein 1; Met, metformin; MTT, 3-(4,5-dimethyl2-thiazolyl)-2,5-diphenyl-2H-tetrazolium bromide; NBDH, 7-hydrazino-4-nitrobenzo-2,1,3oxadiazole; NHLF, human normal lung fibroblasts; OGTT, oral glucose tolerance test; ORAC, oxygen radical absorbing capacity; PE, petroleum ether; $p \mathrm{NPG}, p$-nitrophenyl- $\alpha$-Dglucopyranoside; PPA, porcine pancreatic $\alpha$-amylase; RIP, rat intestinal acetone powder; ROS, reactive oxygen species; RPMI, Roswell Park Memorial Institute medium; SD, standard diet; TBA, 2-thiobarbituric acid; TBARS, thiobarbituric acid-reactive substances; TFC, total flavonoid content; TNF- $\alpha$, tumor necrosis factor- $\alpha$; TPC, total phenolic content; TRAP, total radical antioxidant potential; $\mathrm{XO}$, xanthine oxidase.

Table 1 Total phenolic (TPC), total flayonoid (TFC) contents and concentrations of phenolic compounds ${ }^{a}$ in $A$. radiata extracts detected by HPLC-DAD.

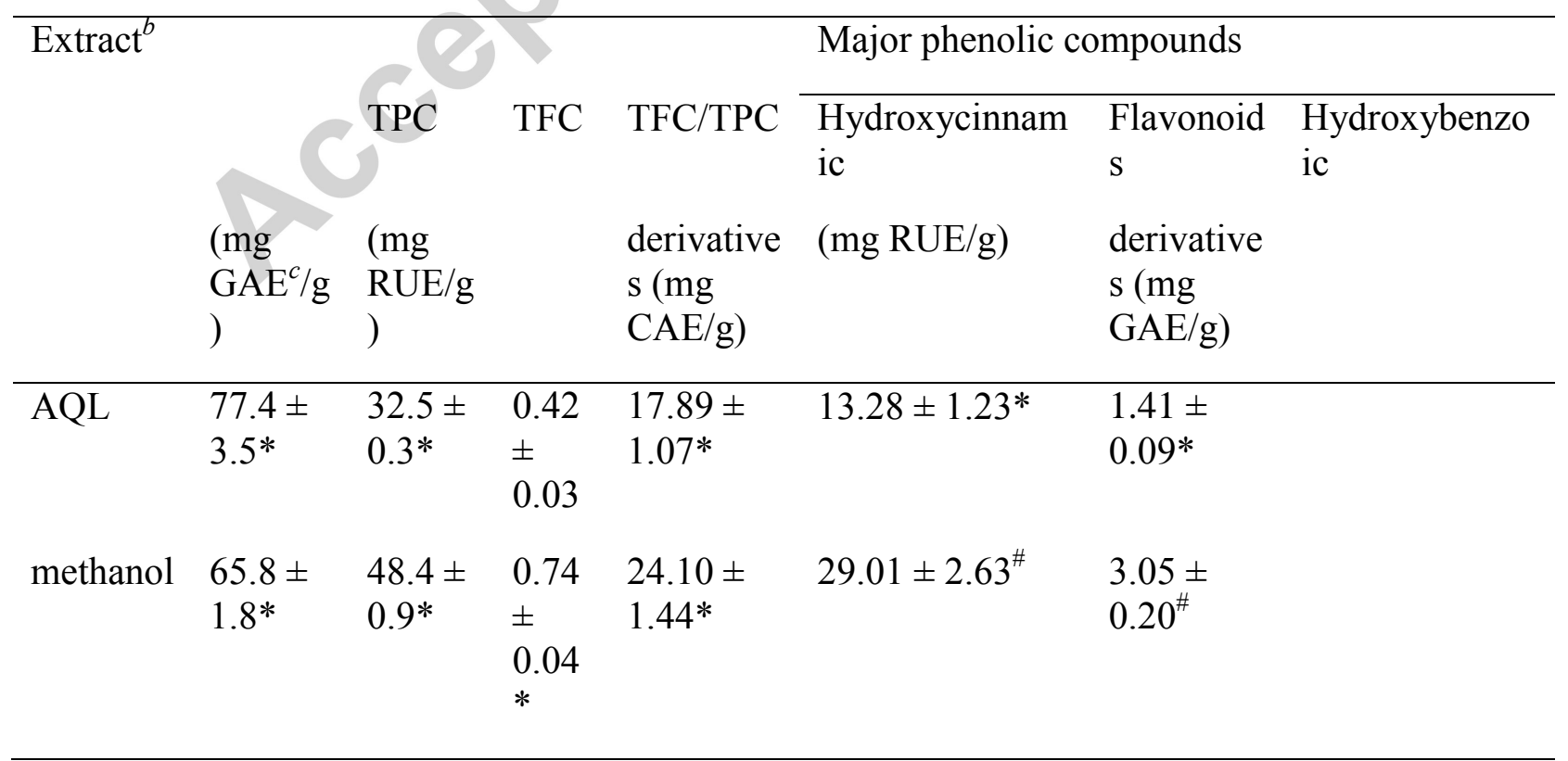




\begin{tabular}{|c|c|c|c|c|c|c|}
\hline $\begin{array}{l}\text { petroleu } \\
\text { m ether }\end{array}$ & $\begin{array}{l}29.9^{ \pm} \\
1.2^{\S}\end{array}$ & $\begin{array}{l}15.5 \pm \\
0.6^{\S}\end{array}$ & $\begin{array}{l}0.51 \\
\pm \\
0.04\end{array}$ & $\begin{array}{l}4.05 \pm \\
0.38^{\S}\end{array}$ & $1.73 \pm 0.10^{\S}$ & $\begin{array}{l}0.47 \pm \\
0.03^{\S}\end{array}$ \\
\hline $\begin{array}{l}\text { ethyl } \\
\text { acetate }\end{array}$ & $\begin{array}{l}158.9 \pm \\
5.3^{\ddagger}\end{array}$ & $\begin{array}{l}63.1 \pm \\
1.8^{\#}\end{array}$ & $\begin{array}{l}0.40 \\
\pm \\
0.05\end{array}$ & $\begin{array}{l}90.91 \pm \\
5.16^{\dagger}\end{array}$ & $66.82 \pm 13.81^{*}$ & $\mathrm{nd}^{d}$ \\
\hline $\begin{array}{l}n- \\
\text { butanol }\end{array}$ & $\begin{array}{l}122.5 \pm \\
3.2^{\#}\end{array}$ & $\begin{array}{l}59.6 \pm \\
1.1^{\#}\end{array}$ & $\begin{array}{l}0.48 \\
\pm \\
0.02\end{array}$ & $\begin{array}{l}56.38 \pm \\
3.20^{\#}\end{array}$ & $39.65 \pm 2.85^{\#}$ & $\begin{array}{l}3.6 \pm \\
0.23^{\#}\end{array}$ \\
\hline $\begin{array}{l}\text { AR } \\
\text { fraction }\end{array}$ & $\begin{array}{l}36.9^{£} \\
1.3^{\S}\end{array}$ & $\begin{array}{l}8.3^{\ddagger} \\
0.1^{\S}\end{array}$ & $\begin{array}{l}0.22 \\
\pm \\
0.01 \\
\S\end{array}$ & $\begin{array}{l}6.68 \pm \\
0.40^{\S}\end{array}$ & nd & nd \\
\hline
\end{tabular}

${ }^{a}$ Values are expressed per gram of extract and represent the mean \pm SEM of 3-6 independent experiments made in triplicate. ${ }^{b} \mathrm{AQL}$, lyophilized aqueous extract; AR, aqueous residual. ${ }^{c} \mathrm{GAE}$, gallic acid equivalents; RUE, rutin equivalents; CAE, caffeic acid equivalents. ${ }^{d}$ nd: not detected. Statistics: the same symbols $*,{ }^{\sharp}{ }^{*}$ or $*$ indicate that values are significantly different $(P<0.02)$ from others by one-way ANOVA followed by Newman-Keuls multiple comparisons test.

Table 2 Antioxidant capacities ${ }^{a}$ in the DPPH, ORAC and TRAP assays.

\begin{tabular}{|c|c|c|c|c|}
\hline \multirow{2}{*}{$\begin{array}{l}\text { Extract or } \\
\text { compound }\end{array}$} & DPPH & & ORAC & TRAP \\
\hline & $\mathrm{IC}_{50}(\mu \mathrm{g} / \mathrm{mL})$ & $\mathrm{TIC}_{50}(\min )^{b}$ & $\begin{array}{l}(\mu \mathrm{mole} \\
\left.\mathrm{TE}^{\mathrm{c}} / \mathrm{g}\right)\end{array}$ & $\begin{array}{l}\text { ( } \mu \text { mole } \\
\mathrm{TE} / \mathrm{g})\end{array}$ \\
\hline AQL & $130.3 \pm 4.3^{*}$ & $23.7 *$ & $\begin{array}{l}1390 \pm \\
50 *\end{array}$ & $\begin{array}{l}512.4 \pm \\
21.2^{*}\end{array}$ \\
\hline methanol & $140.3 \pm 5.2 *$ & 46.1 & $\begin{array}{l}1475 \pm \\
95^{*}\end{array}$ & $\begin{array}{l}498.5 \pm \\
19.9^{*}\end{array}$ \\
\hline petroleum ether & $518.7 \pm 35.7^{\S}$ & 42.7 & $\begin{array}{l}363 \pm \\
11^{\S}\end{array}$ & $\begin{array}{l}15.3 \pm \\
4.2^{\S}\end{array}$ \\
\hline
\end{tabular}




\begin{tabular}{lllll}
\hline ethyl acetate & $43.5 \pm 0.1^{\#}$ & $22.6^{*}$ & $3900 \pm$ & 935.0 \\
& & & $20^{\sharp}$ & $\pm 44.0^{\#}$ \\
$n$-butanol & $47.9 \pm 2.6^{\#}$ & $24.6^{*}$ & $3315 \pm$ & $787.7 \pm$ \\
& & & $98^{\#}$ & $45.2^{\#}$ \\
\multirow{2}{*}{ AR fraction } & $283.3 \pm 25.1^{\S}$ & 59.3 & $503 \pm$ & $32.9 \pm$ \\
& & & $69^{\S}$ & $6.8^{\S}$ \\
metformin & $>500$ & & $\sim 0.02$ & $\sim 0.02$ \\
\hline
\end{tabular}

${ }^{a}$ Values represent the mean \pm SEM of 3-6 independent experiments made in triplicate. ${ }^{b}$ Time to reach the steady state at $\mathrm{IC}_{50}$. ${ }^{c}$ Trolox equivalent. Statistics: the same symbols *, $\$$ \# or * indicate that values are significantly different $(P<0.02)$ from others by one-way ANOVA followed by Newman-Keuls multiple comparisons test.

Table 3 Xanthine oxidase (XO) inhibition, superoxide quenching, and metal chelating capacity $(\mathrm{MCC})^{a}$.

\begin{tabular}{llll}
\hline $\begin{array}{l}\text { Extract or } \\
\text { compound }\end{array}$ & $\begin{array}{l}\mathrm{XO} \text { inhibition } \\
\mathrm{IC}_{50}(\mu \mathrm{g} / \mathrm{mL})\end{array}$ & $\begin{array}{l}\text { Superoxide quenching } \\
\mathrm{IC}_{50}(\mu \mathrm{g} / \mathrm{mL})\end{array}$ & $\begin{array}{l}\mathrm{MCC} \\
(\mu \mathrm{mol} \text { EDTAE } / \mathrm{g})^{b}\end{array}$ \\
\hline $\mathrm{AQL}$ & $531.0 \pm 6.1^{*}$ & $0.222 \pm 0.005^{*}$ & $40.1 \pm 4.3^{*}$ \\
methanol & $309.3 \pm 8.7^{\dagger}$ & $0.267 \pm 0.007^{*}$ & $35.4 \pm 4.7^{*}$ \\
petroleum ether & $>2400^{\S}$ & $0.694 \pm 0.018^{\S}$ & $70.9 \pm 9.2^{*}$ \\
ethyl acetate & $120.3 \pm 8.2^{\#}$ & $0.145 \pm 0.005^{\#}$ & $15.2 \pm 0.9^{\#}$ \\
$n$-butanol & $352.0 \pm 8.7^{\dagger}$ & $0.186 \pm 0.009^{\#}$ & $10.0 \pm 1.4^{\#}$ \\
AR fraction & $>2400^{\S}$ & $0.554 \pm 0.005^{\S}$ & $19.0 \pm 0.7^{\#}$ \\
caffeic acid & $19.5 \pm 2.1^{\ddagger}$ & $0.013 \pm 0.000^{\ddagger}$ & $123.4 \pm 1.9^{\dagger}$ \\
quercetin & $4.2 \pm 0.2^{\ddagger}$ & $0.083 \pm 0.006^{\ddagger}$ & $102.1 \pm 1.2^{\ddagger}$ \\
gallic acid & $41.1 \pm 1^{\ddagger}$ & $0.002 \pm 0.000^{\ddagger}$ & $88.2 \pm 1.8^{\ddagger}$ \\
allopurinol & $1.1 \pm 0.1$ & - & - \\
\hline
\end{tabular}




metformin $\quad>1000 \quad>100$

${ }^{a}$ Values represent the mean \pm SEM of 3-6 independent experiments made in triplicate. ${ }^{b}$ EDTA equivalent. Statistics: the same symbols $*,{ }^{\S},{ }^{*},{ }^{*}$ or ${ }^{\dagger}$ indicate that values are significantly different $(P<0.05)$ from others by one-way ANOVA followed by Newman-Keuls multiple comparisons test.

Table 4 Inhibitory activities against porcine pancreatic $\alpha$-amylase (PPA) and $\alpha$-glucosidases from $S$. cerevisiae (SC) and rat intestinal acetone powder (RIP) ${ }^{a}$.

\begin{tabular}{|c|c|c|c|c|c|c|}
\hline \multirow{2}{*}{$\begin{array}{l}\text { Extract or } \\
\text { compound }\end{array}$} & \multicolumn{2}{|c|}{$\alpha$-amylase (PPA) } & \multicolumn{2}{|c|}{$\alpha$-glucosidase (SC) } & \multicolumn{2}{|c|}{$\alpha$-glucosidase (RIP) } \\
\hline & $\mathrm{IC}_{50}(\mu \mathrm{g} / \mathrm{mL})$ & Inhibition $(\%)^{b}$ & $\begin{array}{l}\mathrm{IC}_{50} \\
(\mu \mathrm{g} / \mathrm{mL})\end{array}$ & $\begin{array}{l}\text { Inhibition } \\
(\%)^{c}\end{array}$ & $\begin{array}{l}\mathrm{IC}_{50} \\
(\mu \mathrm{g} / \mathrm{mL})\end{array}$ & $\begin{array}{l}\text { Inhibition } \\
(\%)^{d}\end{array}$ \\
\hline AQL & $\mathrm{nm}^{e}$ & $27.7 \pm 2.4^{*}$ & $\mathrm{~nm}$ & $\begin{array}{l}34.6 \pm \\
1.7^{*}\end{array}$ & $\begin{array}{l}992 \pm \\
40 *\end{array}$ & $\begin{array}{l}50.5 \pm \\
1.0^{*}\end{array}$ \\
\hline methanol & $\mathrm{nm}$ & $35.9 \pm 2.9^{*}$ & $\mathrm{~nm}$ & $\begin{array}{l}17.7 \pm \\
3.1^{\S}\end{array}$ & $\mathrm{nm}$ & $\begin{array}{l}18.3 \pm \\
0.1^{\S}\end{array}$ \\
\hline $\begin{array}{l}\text { ethyl } \\
\text { acetate }\end{array}$ & $135.7 \pm 12.4^{\S}$ & $89.3 \pm 3.2^{\S}$ & $\mathrm{nm}$ & $\begin{array}{l}38.3 \pm \\
6.1^{*}\end{array}$ & $\begin{array}{l}837 \pm \\
25^{\S}\end{array}$ & $\begin{array}{l}73.2 \pm \\
7.8^{\#}\end{array}$ \\
\hline$n$-butanol & $254.7 \pm 5.2^{\#}$ & $55.2 \pm 1.2^{\#}$ & $\mathrm{~nm}$ & $\begin{array}{l}24.8 \pm \\
3.1^{\#}\end{array}$ & $\begin{array}{l}561 \pm \\
53^{\#}\end{array}$ & $\begin{array}{l}64.5 \pm \\
2.1\end{array}$ \\
\hline acarbose & $0.57 \pm 0.03$ & $>99$ & $\begin{array}{l}114.4 \pm \\
3.9\end{array}$ & $\begin{array}{l}63.7 \pm \\
2.2\end{array}$ & $\begin{array}{l}18.9 \pm \\
0.1\end{array}$ & $\begin{array}{l}62.4 \pm \\
2.6\end{array}$ \\
\hline luteolin & $4.58 \pm 0.52$ & $>99$ & $8.8 \pm 0.4$ & $\begin{array}{l}84.6 \pm \\
0.8\end{array}$ & $\mathrm{~nm}$ & $\begin{array}{l}17.1 \pm \\
1.9\end{array}$ \\
\hline myricetin & $7.31 \pm 0.54$ & $61.2 \pm 2.8$ & $5.2 \pm 0.4$ & $\begin{array}{l}89.5 \pm \\
1.6\end{array}$ & $\mathrm{~nm}$ & $\begin{array}{l}25.3 \pm \\
1.1\end{array}$ \\
\hline miglitol & $\mathrm{nm}$ & $24.9 \pm 4.6$ & $\mathrm{~nm}$ & $\begin{array}{l}20.6 \pm \\
2.2\end{array}$ & $\begin{array}{l}19.6 \pm \\
0.1\end{array}$ & $\begin{array}{l}67.3 \pm \\
1.8\end{array}$ \\
\hline voglibose & $\mathrm{nm}$ & $23.5 \pm 2.9$ & $\mathrm{~nm}$ & $12.5 \pm$ & $0.35 \pm$ & $70.9 \pm$ \\
\hline
\end{tabular}




\begin{tabular}{|c|c|c|c|c|c|c|}
\hline & & & & 3.0 & 0.05 & 1.1 \\
\hline metformin & $\mathrm{nm}$ & $12.8 \pm 1.7$ & $\mathrm{~nm}$ & $\begin{array}{l}14.3 \pm \\
2.0\end{array}$ & $\mathrm{~nm}$ & $\begin{array}{l}11.2 \pm \\
0.9\end{array}$ \\
\hline
\end{tabular}

$\underline{\text { Table } 4 \text { (continued) }}$

${ }^{a}$ Values represent the mean \pm SEM of 3-5 independent experiments made in triplicate.

${ }^{b}$ Concentrations giving maximal inhibition: extracts, $286 \mu \mathrm{g} / \mathrm{mL}$; acarbose, $6.2 \mu \mathrm{g} / \mathrm{mL}$; luteolin and myricetin, $42 \mu \mathrm{g} / \mathrm{mL}$; miglitol, voglibose and metformin, $62 \mu \mathrm{g} / \mathrm{mL}$. ${ }^{c}$ Concentrations giving maximal inhibition: extracts, $1.4 \mathrm{mg} / \mathrm{mL}$; acarbose, $274 \mu \mathrm{g} / \mathrm{mL}$; luteolin and myricetin, 20 $\mu \mathrm{g} / \mathrm{mL}$; miglitol, voglibose and metformin, $42 \mu \mathrm{g} / \mathrm{mL}$. ${ }^{d}$ Concentrations giving maximal inhibition: extracts, $1.0 \mathrm{mg} / \mathrm{mL}$; acarbose, $93 \mu \mathrm{g} / \mathrm{mL}$; miglitol and voglibose, $3 \mu \mathrm{g} / \mathrm{mL}$, metformin, $42 \mu \mathrm{g} / \mathrm{mL}$. ${ }^{e}$ not measurable. Statistics: the same symbols ${ }^{*}{ }^{\S}$ or ${ }^{\#}$ indicate that values are significantly different $(P<0.05)$ from others by one-way ANOVA followed by NewmanKeuls multiple comparisons test.

Table 5 Cytotoxicity against human lung cancer cells (A549) and normal fibroblasts (NHLF) ${ }^{a}$.

\begin{tabular}{lllll}
\hline Extract or & MTT & & FMCA \\
compound & $\mathrm{IC}_{50}(\mu \mathrm{g} / \mathrm{mL})^{b}$ & & $\mathrm{IC}_{50}(\mu \mathrm{g} / \mathrm{mL})$ & \\
& $\mathrm{A} 549$ & $\mathrm{NHLF}$ & $\mathrm{A} 549$ & $\mathrm{NHLF}$ \\
\hline AQL & $360 \pm 12^{*}$ & $270 \pm 13^{*}$ & $365 \pm 21^{*}$ & $252 \pm 6^{*}$ \\
methanol & $143 \pm 2^{\S}$ & $35 \pm 3^{\S}$ & $123 \pm 2^{\S}$ & $23 \pm 1^{\S}$ \\
ethyl & $118 \pm 2^{\#}$ & $24 \pm 1^{\#}$ & $108 \pm 2^{\#}$ & $17 \pm 2^{\#}$ \\
acetate & & & & \\
$n$-butanol & $>400$ & $>400$ & $>400$ & $>400$ \\
metformin & $>400$ & $>400$ & $>400$ & \\
& & & & \\
\hline
\end{tabular}


${ }^{a}$ Values represent the mean \pm SEM of $4-8$ independent experiments made in triplicate. ${ }^{b} \mathrm{IC}_{50}$ is defined as the concentration of sample resulting in 50\% cell viability after $48 \mathrm{~h}$ and calculated from concentration-response curves. Statistics: the same symbols $*{ }^{\S}$ or ${ }^{\#}$ indicate that values are significantly different $(P<0.05)$ from others by one-way ANOVA followed by Newman-Keuls multiple comparisons test.

Table 6 Antidiabetic, antioxidant and anti-inflammatory effects of treatments in C57BL/6J mice ${ }^{a}$.

\begin{tabular}{|c|c|c|c|c|c|c|c|}
\hline \multirow[t]{2}{*}{ Parameters } & \multicolumn{7}{|c|}{ Experimental groups $^{b}$} \\
\hline & \multicolumn{2}{|c|}{ Control SE HFD } & {$[\mathrm{HFD}+\mathrm{AQ}$} & \multicolumn{4}{|c|}{$\left[\mathrm{HFD}+\mathrm{AQ}\left[\mathrm{HF}+n-\mathrm{Bu}\left(\left[\mathrm{HFD}+\mathrm{Met}\left[\mathrm{HFD}+\mathrm{Met}_{75}+\mathrm{AQ}\right.\right.\right.\right.\right.$} \\
\hline Body weight & $29.8 \pm$ & $41.9 \pm$ & $34.8 \pm$ & $35.8 \pm$ & $33.6 \pm$ & $33.9 \pm$ & $31.7 \pm 0.7^{\dagger}$ \\
\hline (g) & 0.8 & $1.0 * * *$ & $0.9^{* \dagger}$ & $1.0 *+*$ & $0.9^{* \dagger}$ & $0.4^{* \dagger}$ & \\
\hline Food intake & $286 \pm 6$ & $279 \pm 12$ & $281 \pm 9$ & $282 \pm 4$ & $285 \pm 8$ & $283 \pm 1$ & $285 \pm 3$ \\
\hline$(\mathrm{g})^{c}$ & & & & & & & \\
\hline Total fat mass & $2.91 \pm$ & $8.99 \pm$ & $4.87 \pm$ & $5.31 \pm$ & $4.07 \pm$ & $4.61 \pm$ & $3.71 \pm 0.06^{\dagger}$ \\
\hline (g) & 0.03 & $0.12 *$ & $0.04 * \S$ & $0.08 * \S$ & $0.18^{* \dagger}$ & $0.07 * \S$ & \\
\hline Glucose & $85.9 \pm$ & $260.4 \pm$ & $135.7 \pm$ & $143.5 \pm$ & $137.0 \pm$ & $124.2 \pm$ & $107.5 \pm 2.3^{\dagger}$ \\
\hline$(\mathrm{mg} / \mathrm{dL})$ & 1.3 & $7.4 * * *$ & $4.4 * \dagger$ & $3.8^{\dagger \dagger}$ & $19.8^{* \dagger}$ & $2.5 * \dagger$ & \\
\hline Insulin & $1.8 \pm 0.2$ & $4.8 \pm$ & $3.1 \pm 0.4^{\dagger}$ & $3.3 \pm$ & $2.7 \pm 0.2^{\dagger}$ & $2.5 \pm 0.3^{\dagger}$ & $2.2 \pm 0.2^{\dagger}$ \\
\hline$(\mathrm{ng} / \mathrm{mL})$ & $\gamma$ & $0.5 * * *$ & & $0.3 * \dagger$ & & & \\
\hline $\mathrm{HbA}_{1 \mathrm{C}}(\%)^{d}$ & $5.1 \pm 0.1$ & $8.6 \pm$ & $5.9 \pm 0.3^{\dagger}$ & $6.3 \pm$ & $5.8 \pm 0.1^{\dagger}$ & $5.8 \pm 0.2^{\dagger}$ & $5.3 \pm 0.2^{\dagger}$ \\
\hline & & $0.3 * * *$ & & $0.2 * \dagger$ & & & \\
\hline Leptin & $7.1 \pm 1.2$ & $36.8 \pm$ & $15.8 \pm$ & $18.7 \pm$ & $15.3 \pm$ & $24.0 \pm$ & $14.3 \pm 1.1^{\dagger}$ \\
\hline$(\mathrm{ng} / \mathrm{mL})$ & & $2.3 * * *$ & $1.3^{* \dagger}$ & $1.7^{* \dagger}$ & $2.2^{\dagger}$ & $1.9 * \dagger$ & \\
\hline T-cholesterol & $53.8 \pm$ & $115.8 \pm$ & $76.8 \pm$ & $88.0 \pm$ & $67.8 \pm$ & $85.4 \pm$ & $80.1 \pm 3.9^{* * \dagger}$ \\
\hline$(\mathrm{mg} / \mathrm{dL})$ & 5.8 & $6.5 * * *$ & $1.2 * * \dagger$ & $3.8^{* * \S}$ & $2.3^{\dagger}$ & $3.7 * * \dagger$ & \\
\hline
\end{tabular}




\begin{tabular}{llllllll}
\hline Triglycerides & $64.9 \pm 2.1$ & $111.7 \pm$ & $82.1 \pm$ & $89.8 \pm$ & $69.8 \pm$ & $78.3 \pm$ & $72.7 \pm 3.9^{\dagger}$ \\
$(\mathrm{mg} / \mathrm{dL})$ & & $9.5^{* * *}$ & $5.1^{\dagger}$ & $3.9^{* * \S}$ & $3.6^{\dagger}$ & $2.2^{\dagger}$ & \\
& & & & & & & \\
Triglycerides & $0.69 \pm$ & $6.96 \pm$ & $2.59 \pm$ & $2.93 \pm$ & $1.99 \pm$ & $2.09 \pm$ & $1.71 \pm 0.24^{\dagger}$ \\
in & 0.04 & $1.00^{* * *}$ & $0.45^{\dagger}$ & $0.31^{* \S}$ & $0.29^{\dagger}$ & $0.23^{\dagger}$ &
\end{tabular}

liver tissue $(\mathrm{mg} / \mathrm{g})$

$\underline{\text { Table } 6 \text { (continued) }}$

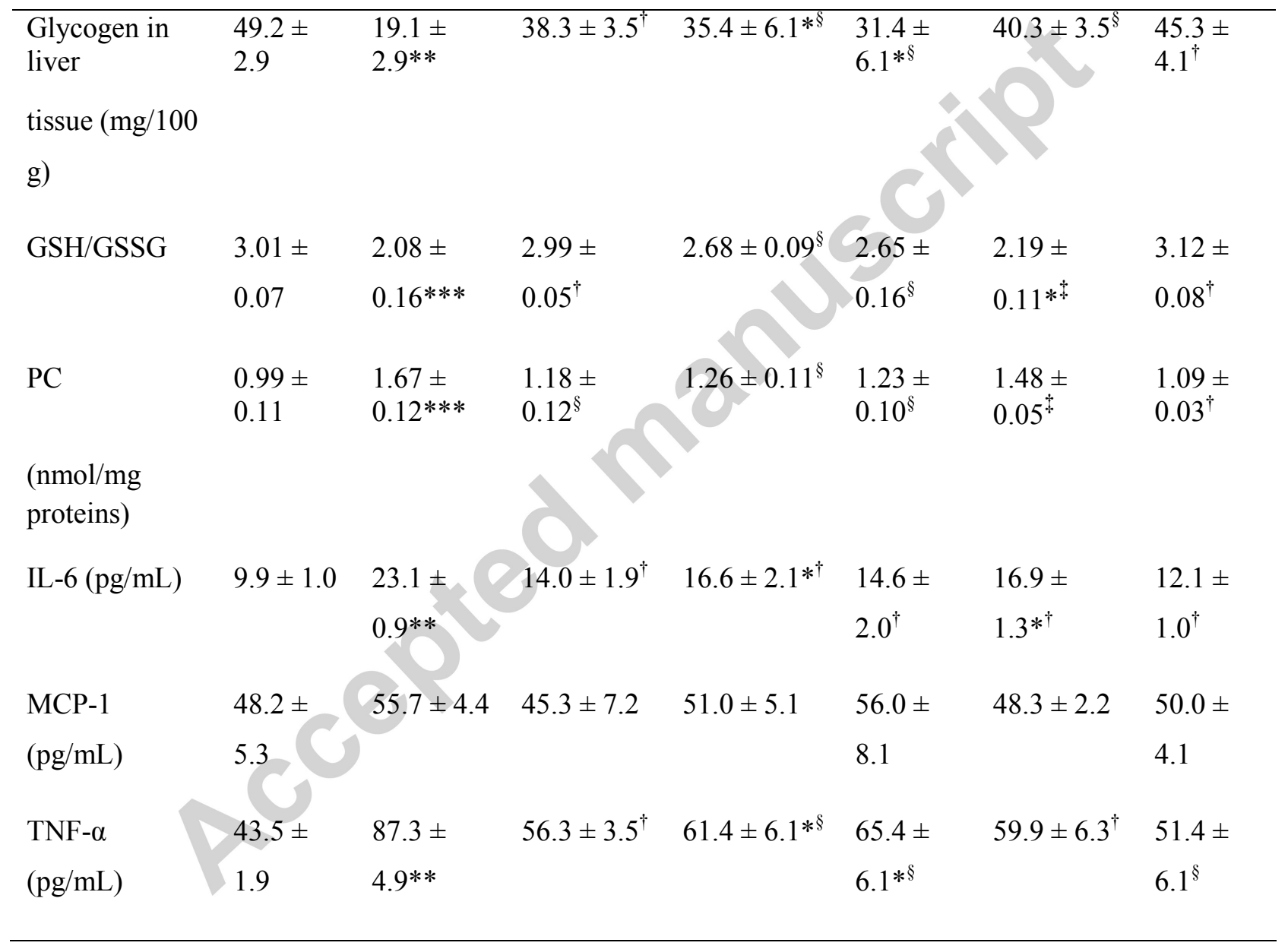

\footnotetext{
${ }^{a}$ Values represent the mean \pm SEM of 6-12 independent experiments made in triplicate. Assays were performed in blood plasma unless otherwise noted. ${ }^{b}$ Groups and treatments: SD, control mice fed a standard diet; HFD, mice fed a high-fat diet (60\% fat); AQL, lyophilized aqueous
} 
extract; $n$-BuOH, butanol extract, Met, metformin. Extracts and metformin were administered at $150 \mathrm{mg} / \mathrm{kg} /$ day for 12 weeks consecutive to an HFD induction of 16 weeks, except for groups with $\mathrm{AQL}_{75}$ and $\mathrm{Met}_{75}$ for which the doses were $75 \mathrm{mg} / \mathrm{kg} / \mathrm{day} .{ }^{c}$ Average food consumed per mouse pooled over 12 weeks. ${ }^{d}$ Abbreviations: $\mathrm{HbA}_{1 \mathrm{c}}$, glycosylated hemoglobin; T-cholesterol, total cholesterol; GSH/GSSG; ratio of reduced-to-oxidized glutathione; PC, protein carbonyls; IL-6, interleukin-6; MCP-1, monocyte-chemoattractant protein 1; TNF- $\alpha$, tumor necrosis factor$\alpha$. Statistics: values are significantly different from controls $\left({ }^{*} P<0.05, * * P<0.01\right.$ and $* * * P<$ 0.001), HFD $\left({ }^{\S} P<0.05\right.$ and $\left.{ }^{\dagger} P<0.001\right)$ and ${ }^{\ddagger} P<0.05$ vs $\left[\mathrm{Met}_{75}+\mathrm{AQL}_{75}\right.$, by one-way ANOVA followed by Tukey's multiple comparison test. 